\title{
Are simulated aerosol-induced effects on deep convective clouds strongly dependent on saturation adjustment?
}

\author{
Z. J. Lebo ${ }^{1, *}$, H. Morrison ${ }^{2}$, and J. H. Seinfeld ${ }^{1,3}$ \\ ${ }^{1}$ Environmental Science and Engineering, California Institute of Technology, Pasadena, 91125, CA, USA \\ ${ }^{2}$ Mesoscale and Microscale Meteorology Division, National Center for Atmospheric Research, Boulder, 80307, CO, USA \\ ${ }^{3}$ Chemical Engineering, California Institute of Technology, Pasadena, 91125, CA, USA \\ *now at: Mesoscale and Microscale Meteorology Division, National Center for Atmospheric Research, Boulder, 80307, \\ $\mathrm{CO}, \mathrm{USA}$
}

Correspondence to: Z. J. Lebo (lebo@ucar.edu)

Received: 18 March 2012 - Published in Atmos. Chem. Phys. Discuss.: 19 April 2012

Revised: 21 September 2012 - Accepted: 10 October 2012 - Published: 30 October 2012

\begin{abstract}
Three configurations of a bulk microphysics scheme in conjunction with a detailed bin scheme are implemented in the Weather Research and Forecasting (WRF) model to specifically address the role of the saturation adjustment assumption (i.e., condensing/evaporating the surplus/deficit water vapor relative to saturation in one time step) on aerosol-induced invigoration of deep convective clouds. The bulk model configurations are designed to treat cloud droplet condensation/evaporation using either saturation adjustment, as employed in most bulk models, or an explicit representation of supersaturation over a time step, as used in bin models. Results demonstrate that the use of saturation adjustment artificially enhances condensation and latent heating at low levels and limits the potential for an increase in aerosol concentration to increase buoyancy at mid to upper levels. This leads to a small weakening of the time- and domain-averaged convective mass flux $(\sim-3 \%)$ in polluted compared to clean conditions. In contrast, the bin model and bulk scheme with explicit prediction of supersaturation simulate an increase in latent heating aloft and the convective updraft mass flux is weakly invigorated $(\sim 5 \%)$. The bin model also produces a large increase in domainmean cumulative surface precipitation in polluted conditions $(\sim 18 \%)$, while all of the bulk model configurations simulate little change in precipitation. Finally, it is shown that the cold pool weakens substantially with increased aerosol loading when saturation adjustment is applied, which acts to reduce the low-level convergence and weaken the convective dynamics. With an explicit treatment of supersaturation in
\end{abstract}

the bulk and bin models there is little change in cold pool strength, so that the convective response to polluted conditions is influenced more by changes in latent heating aloft. It is concluded that the use of saturation adjustment can explain differences in the response of cold pool evolution and convective dynamics with aerosol loading simulated by the bulk and bin models, but cannot explain large differences in the response of surface precipitation between these models.

\section{Introduction}

Recent studies have investigated the effects of increased aerosol loading on the behavior and response of deep convective clouds (e.g., Khain et al., 2004; Khain and Pokrovsky, 2004; Khain et al., 2005; Wang, 2005; Koren et al., 2005; Grabowski, 2006; Seifert and Beheng, 2006; Teller and Levin, 2006; Van den Heever et al., 2006; Fan et al., 2007; Tao et al., 2007; Van den Heever and Cotton, 2007; Khain et al., 2008; Lee et al., 2008a,b; Rosenfeld et al., 2008; Fan et al., 2009; Khain and Lynn, 2009; Koren et al., 2010; Noppel et al., 2010; Ekman et al., 2011; Lee, 2011; Lebo and Seinfeld, 2011; Grabowski and Morrison, 2011; Seifert et al., 2012; Morrison, 2012; Tao et al., 2012). Changes in cloud properties resulting from aerosol loading can have potentially significant effects on the radiative forcing, precipitation patterns and amounts, and storm severity. The inherent complexity of untangling aerosol effects in a system with numerous, interacting dynamical and microphysical feedbacks 
is highly challenging. This is especially true in a mixed-phase convective environment. Although the initial effect of an increase in aerosol loading may be to suppress the collisioncoalescence process and thus mitigate the formation of precipitation within a warm cloud or the warm region of a mixed-phase cloud (i.e., Gunn and Phillips, 1956; Squires, 1958; Albrecht, 1989), feedbacks with the environment or changes in the microphysical process rates in other regions of the cloud may result in a negligible change in precipitation, or even potentially an increase.

Specific effects of aerosol perturbations on the strength of convection and cumulative precipitation through their impact on cloud microphysics (i.e., indirect aerosol effects) have been suggested recently from both satellite observational analyses and numerical modeling studies. Conceptually, we categorize the conclusions of these works as follows:

1. Increased Buoyancy - Rosenfeld et al. (2008) provided a conceptual model describing how an increase in aerosol number concentration can lead to a decrease in collision-coalescence and thus an increase in the mass of liquid hydrometeors that are lofted above the freezing level based upon previous, more detailed studies (e.g., Khain et al., 2005; Koren et al., 2005; Van den Heever et al., 2006; Seifert and Beheng, 2006). There, the particles freeze and the resulting latent heating provides a positive buoyancy contribution (and hence an increase in vertical velocity). Note that an increase in condensate loading aloft has offsetting effects on buoyancy, but under some conditions there is an invigoration, all else being equal. There may be either an increase or decrease in surface precipitation depending in part on factors such as environmental relative humidity (e.g., Rosenfeld et al., 2008; Khain and Lynn, 2009; Lebo and Seinfeld, 2011).

2. Cold Pool Strengthening - Lee et al. (2008a), and Lee (2011) found that an increase in aerosol loading leads to an increase in low-level convergence, resulting from an increase in evaporation and a stronger cold pool. Tao et al. (2007) showed that in polluted environments, evaporation may increase or decrease, producing a stronger or weaker cold pool depending upon the environmental conditions. On the other hand, Van den Heever and Cotton (2007) and Morrison (2012) showed that a weakening in cold pool strength arises from an increase in aerosol number concentration.

3. Cloud Deepening and Detrainment - Stevens and Feingold (2009) postulated that in polluted conditions, the cloud hydrometeors ought to be more numerous and smaller and consequently, more likely to evaporate or sublimate when detrained near cloud top. An increase in evaporation or sublimation at cloud top will moisten environmental air, allowing subsequent clouds to deepen by reducing entrainment of dry air. Changes in evaporative cooling at the lateral cloud edges associated with smaller droplets in polluted conditions can also impact cloud-scale vorticity and entrainment (e.g., Xue and Feingold, 2006). These effects have been studied primarily for shallow cumulus and cumulus congestus; their impact on deep convective clouds is potentially important but highly uncertain.

While it is convenient to categorize conceptually the different mechanisms by which an aerosol perturbation can alter the dynamics of moist deep convection, in reality, a combination of these effects is likely to occur and the importance of specific mechanisms is likely to vary from case to case (c.f., Morrison, 2012). Given this complexity, it is not surprising that simulations of the resulting changes in surface precipitation with aerosol loading are inconsistent among modeling studies (e.g., see Table 5 in Tao et al., 2007 and Table 4 in Tao et al., 2012). Van den Heever et al. (2006) demonstrated using a three-dimensional (3-D) cloud resolving model (CRM) that an increase in cloud condensation nuclei (CCN), giant CCN (GCCN), and/or ice nuclei (IN) results in a decrease in precipitation. Similar results have been reported by Fan et al. (2009) using a 2-D CRM with bin microphysics in high wind shear environments, Lebo and Seinfeld (2011) using a 3-D CRM with bin microphysics, and Khain and Lynn (2009) using a 3-D CRM with bulk microphysics. However, these same studies, when using a different microphysics model, predicted that increased aerosol loading can lead to an increase in precipitation. For example, Lebo and Seinfeld (2011) compared the results of both bin and bulk microphysics models for an increase in aerosol number concentration and found that the bin model predicted a decrease in precipitation while the bulk model predicted the opposite. On the other hand, for increased aerosol loading, Khain and Lynn (2009) predicted an increase in precipitation using a bin microphysics scheme, and a decrease with a bulk microphysics scheme.

Previous studies have also disagreed on the potential for aerosol loading to invigorate convective dynamics. Some studies have predicted negligible changes in the strength of convection (e.g., Khain and Lynn, 2009), or a weakening, especially in high shear environments (e.g., Fan et al., 2009). Other studies have indicated a strengthening of convective drafts (e.g., Khain et al., 2005; Lebo and Seinfeld, 2011). A difficulty in comparing these studies is that different metrics were used to define changes in convective strength with aerosol loading. For example, Khain and Lynn (2009) and Fan et al. (2009) used the domain-maximum vertical velocity as a way to quantify changes in convective strength. Van den Heever et al. (2006) and Lebo and Seinfeld (2011) presented an alternative metric for invigoration, the mean updraft within the convective core, in which the convective core was defined as all columns in which the mean vertical velocity between two levels, one near cloud base 
and one near cloud top, exceeded $1 \mathrm{~m} \mathrm{~s}^{-1}$. Recently, Morrison (2012) used yet another metric by analyzing changes in the domain-averaged convective mass flux. The convective mass flux was defined in this study as the mean mass flux for all grid points at a given level in which the updraft velocities exceeded $2 \mathrm{~m} \mathrm{~s}^{-1}$, divided by the total area of the domain. Morrison (2012) showed that for a supercell storm, differences between pristine and polluted conditions in the domain-maximum vertical velocity and mean updraft within convective cores (as defined above) had considerably more temporal variability and sensitivity to perturbed initial conditions compared to differences in the domain-averaged convective mass flux, and concluded that the convective mass flux was a more robust metric.

In terms of modification of cold pool dynamics resulting from an aerosol perturbation, Tao et al. (2007) and Lee et al. (2008a) found that low-level evaporation increased with aerosol loading and, consequently, more cooling within the cold pool was simulated. By generating a colder cold pool, the low-level convergence increased and drove stronger mesoscale convection. On the other hand, Van den Heever and Cotton (2007) and Morrison (2012) found the opposite. In these studies, the net evaporation at low levels decreased under polluted conditions, thus weakening the cold pool and reducing low-level convergence. Differences in the sign of the change in cold pool strength among these studies may be related to complex interactions between melting, raindrop mean size, sedimentation, evaporation, and environmental wind shear along cold pool boundaries. More generally, the impact of cold pool strength and low-level shear on storm dynamics is described by "RKW" theory (Rotunno et al., 1988; Weisman and Rotunno, 2004). According to this theory, overall storm strength can either increase or decrease depending upon the relative balance of vorticity between the cold pool circulation and the low-level environmental shear. This picture is qualitatively consistent with modeling studies that have shown changes in convective strength due to increased aerosol loading are dependent upon relative humidity (which affects cold pool strength through rain evaporation) and environmental wind shear (Khain et al., 2008; Fan et al., 2009). Nonetheless, the relationship between increased aerosol loading and cold pool strength is uncertain and more work in this area is needed.

It is also important to point out that most numerical modeling studies of aerosol-induced effects on deep convective clouds have examined the response of individual convective storms. However, Grabowski (2006), Grabowski and Morrison (2011), and Van den Heever et al. (2011) used a Convective-Radiative Quasi-Equilibrium Model to address aerosol effects on deep convection over larger spatiotemporal scales, in a system allowing feedback between numerous interacting clouds and their environment. In these studies, little to no change in domain-mean surface precipitation occurred with increased aerosols because surface precipitation in equilibrium conditions is strongly constrained by the at- mospheric radiative cooling, which was relatively unaffected by aerosols (with fixed surface conditions). Similarly, Seifert et al. (2012) found that while an increase in aerosol number concentration led to large instantaneous, local changes in precipitation, the impact was very small when averaged over larger spatiotemporal scales. They emphasized feedbacks between convection and mesoscale dynamics in explaining the much smaller response when averaged over time and space.

In short, the various numerical modeling studies cited above do not agree on the sign of the effect of an increase in aerosol number concentration on precipitation amount or convective strength. Different environmental conditions among these studies (e.g., shear, relative humidity) likely explain some of these differences (see Fig. 17 in Khain et al., 2008). Other differences can be explained by analysis of the storm-scale response versus the larger system-wide response, as described above. Nonetheless, large differences in simulated aerosol effects have been shown using different microphysics schemes even when all other aspects of the model and case study were identical. In particular, bulk and bin microphysics schemes have produced a different sign of the response of convective dynamics and precipitation to aerosols in several studies (e.g., Li et al., 2009; Khain and Lynn, 2009; Lebo and Seinfeld, 2011; Fan et al., 2012). Thus, one must carefully examine differences between these schemes. Inherently, the algorithms and parameterizations of the various microphysical processes between bulk and bin microphysics models are different. Khain and Lynn (2009), Lebo and Seinfeld (2011) and Fan et al. (2012) suggested that a potential cause of these differences lies in the use of a saturation adjustment scheme to predict droplet condensation in bulk models, versus explicit supersaturation prediction in bin schemes. However, to our knowledge no study has systematically investigated this hypothesis. Kogan and Martin (1994) discussed the error of bulk condensation schemes, but not in comparison detailed bin microphysics. Seifert et al. (2006) did a thorough comparison for bin and bulk model simulations for predicting single-cell convection and squall line development in 2D, finding that the assumptions about ice microphysics and warm-rain autoconversion are most significant in attaining a good agreement between models. However, both of these studies did not examine the treatment of condensation in the light of aerosol effects on supercells. The purpose of the current study is to rigorously test the idea that saturation adjustment has a large impact on the response of deep convection to aerosol loading relative to bin models that explicitly predict supersaturation.

In a saturation adjustment scheme, condensation/evaporation is predicted by simply condensing/evaporating all surplus/deficit in the water vapor mixing ratio relative to the saturation value, i.e., the saturation ratio is adjusted to unity at the end of the time step, after all other microphysical and dynamical (e.g., mixing, advection and adiabatic warming/cooling) processes are calculated. For many applications, i.e., large horizontal 
grid spacing and long model time steps $(\Delta t)$, the model results are not expected to be sensitive to the use of a saturation adjustment scheme for representing cloud liquid condensation/evaporation since for $\Delta t>\approx 1 \mathrm{~min}$, the condensational timescale for cloud droplets is likely shorter than the model time step (e.g., Chuang et al., 1997). In other words, equilibrium conditions can be assumed. Thus, by the end of the time step the drops are able to take up most of the available water vapor surplus (or deficit in the case of evaporation). Moreover, large grid spacings cannot resolve convective dynamics and hence updraft speeds and ambient supersaturations are small. However, as one reduces the domain grid spacing to cloud-resolving scales, updrafts are better resolved and hence supersaturations may be relatively large, while the time step is not long enough for the droplets to take up all of the available water vapor surplus. This may be especially problematic for cloud-resolving simulations of moist deep convection, with large updraft speeds. Hence, forcing the saturation ratio to unity on short timescales can result in excess latent heating that may have potentially important effects on the simulated dynamics. Correspondingly, saturation adjustment in moist downdrafts may produce excessive evaporation and cooling. Previous studies have indicated the important role of evaporation timescale (assumed to be instantaneous using saturation adjustment) on buoyancy reversal and vorticity in shallow convective clouds (e.g., Xue and Feingold, 2006). Impacts of saturation adjustment on downdraft dynamics for moist deep convection have not yet been explored.

The saturation adjustment method also assumes that the bulk condensation/evaporation rates are independent of the droplet microphysical characteristics, whereas, physically, these rates are roughly proportional to the droplet number concentration times the mean droplet size (Pruppacher and Klett, 1997). Hence, in polluted conditions with a relative high droplet concentration in updrafts, the condensation rate for a given total droplet mass mixing ratio will be larger than that in pristine conditions with a lower droplet concentration, all else being equal. This implies differences in condensation rate and hence latent heating can occur between pristine and polluted conditions, subsequently leading to differences in buoyancy and updraft strength. While differences in condensation between pristine and polluted conditions may be initially rather small, the positive feedback between condensation rate, latent heating, and updraft strength can enhance this effect. In other words, an initially small enhancement of latent heating in polluted relative to pristine conditions can increase buoyancy and updraft strength, leading to further increases in latent heating, buoyancy, updraft strength, and so on. This effect cannot be represented by saturation adjustment schemes.

In light of recent studies showing large differences in aerosol-cloud-precipitation interactions and invigoration of moist deep convection, specifically for supercell storms, using either bulk or bin microphysics schemes (e.g., Khain and
Lynn, 2009; Lebo and Seinfeld, 2011), we examine the hypothesis that differences in the sign of aerosol effects on precipitation and convective strength between bulk and bin schemes are sensitive to the use of a saturation adjustment scheme versus explicit treatment of supersaturation. Supercells present an interesting testbed for determining the effect of aerosol perturbations on mesoscale convection for a few reasons. First, this represents a natural continuation of previous studies of aerosol effects on idealized supercell storms (e.g., Khain and Lynn, 2009; Lebo and Seinfeld, 2011; Morrison, 2012). Second, supercells are the most intense type of deep convective system in the atmosphere and are often responsible for producing large hail and spawning dangerous tornadoes (e.g., Houze, 1993). We note that the mesoscale updrafts in supercells are driven by stretching and tilting of environmental vorticity in addition to buoyancy effects (Klemp, 1987), and hence may be expected to be relatively less sensitive to aerosols than other types of deep convection occurring under weaker environmental shear. Nonetheless, previous modeling studies have shown large effects of aerosols on these storms (e.g., Khain and Lynn, 2009; Lebo and Seinfeld, 2011). It is therefore important to understand this behavior and how it differs among models.

In Sect. 2 we describe the bin and bulk models utilized and the necessary modifications to the bulk model to address the potential impact of saturation adjustment on the response of a supercell to aerosol loading. Section 3 discusses the modeling framework, environmental conditions, and sensitivity configurations of test cases. The simulated results are presented in Sect. 4. A brief discussion regarding the potential impact of the results on other cloud types and ambient conditions appears in Sect. 5. Section 6 reviews the key results of the study.

\section{Methods}

In order to analyze potential dependencies of simulated aerosol-induced effects on deep convective clouds on model formulation we utilize, as a benchmark, a detailed bin microphysics scheme (Lebo and Seinfeld, 2011) in conjunction with a two-moment bulk microphysics model (Morrison et al., 2009) that has been modified specifically for the study. There are systematic differences in the representation of all microphysical processes between the bin and bulk microphysics schemes. For specifically addressing how differences in the two models can alter the simulated aerosol induced changes in convective strength, aerosol activation and droplet condensation/evaporation are the first two processes that link changes in aerosol loading (acting as $\mathrm{CCN}$ ) to changes in cloud properties and dynamics. Thus, we present here the essential modifications and details required to rigorously assess the impact of saturation adjustment for condensation/evaporation on the simulations. It is important to note that the representations of additional processes within 
the cloud, e.g., collection, sedimentation, and ice formation processes, are also likely to cause differences in the predicted storm strength and precipitation pattern between bin and bulk microphysics. However, detailed investigation of these processes is beyond the scope of the current study.

\subsection{Bin microphysics model}

We employ the bin microphysics scheme of Lebo and Seinfeld (2011). This scheme predicts droplet activation following Köhler theory from a predefined aerosol distribution. Aerosol particles are regenerated in a one-to-one manner (in other words, for each drop that evaporates during a time step, one aerosol particle is regenerated) and added to the aerosol size bins corresponding to preset distribution parameters. For the purpose of this study, we exclude Brownian Diffusion, thermophoresis, and gravitational collection of aerosol particles, as these are not essential to the good of the work. Thus, the regenerated aerosol size distribution parameters are equivalent to those used to initially populate the domain with aerosol particles.

The new configuration of the bin microphysics scheme includes the treatment of the Hallet-Mossop rime-splintering mechanism (Hallett and Mossop, 1974). The spectral treatment of the cloud particle distributions permits the use of the following relation to predict the rate of production of splinters caused by the riming process $\left(P_{c}\right)$ as (Pruppacher and Klett, 1997):

$$
P_{\mathrm{c}}=\sum_{k=1}^{36} \sum_{j=4}^{36} \frac{1}{250} \pi r_{\mathrm{i}, k}^{2} V_{\mathrm{i}, k} K\left(r_{\mathrm{i}, k}, r_{\mathrm{c}, j}\right) N_{\mathrm{c}, j} f\left(T_{\mathrm{p}}\right)
$$

where the subscripts $i$ and c correspond to ice (here, we include snow and graupel to account for all riming) and cloud drops, subscripts $k$ and $j$ correspond to the ice and cloud droplet bins, respectively (bin 4 of the liquid drop distribution corresponds to drops with a radius of $12.5 \mu \mathrm{m}$ and thus only drops of this size or larger are included in the splintering calculations), $r$ is the spherical-equivalent radius of an ice particle or cloud drop, $K\left(r_{\mathrm{i}, k}, r_{\mathrm{c}, j}\right)$ is the gravitational collection kernel for collisions between ice particles and cloud droplets, $N$ is number concentration in a given bin, and $f\left(T_{\mathrm{p}}\right)$ is defined as a function of particle temperature $\left(T_{\mathrm{p}}\right)$ as

$$
f\left(T_{\mathrm{p}}\right)=\left\{\begin{array}{cc}
0, & T_{\mathrm{p}}>270.1 \mathrm{~K} \\
\left(270.16-T_{\mathrm{p}}\right) / 2, & 270.16 \geq T_{\mathrm{p}} \geq 268.16 \mathrm{~K} \\
\left(T_{\mathrm{p}}-265.16\right) / 3, & 268.16>T_{\mathrm{p}} \geq 265.16 \mathrm{~K} \\
0, & T_{\mathrm{p}}<265.16 \mathrm{~K}
\end{array}\right.
$$

Equation (1) accounts for the observed fact that 1 splinter is produced per 250 collisions of ice particles with drops with a radius larger than $12 \mu \mathrm{m}$.

The representation of sedimentation within the bin model for frozen hydrometeors has been updated using the method of Mitchell (1996), in which power-law relationships are established between the Reynolds number of a falling hydrom- eteor and its Best (or Davies) number. This is used to determine the flow regime and the appropriate relationship between the maximum dimension of a particle and its projected area. Thus, the parameters used in computing the fall speed of frozen hydrometeors are also a function of particle size. Note that this differs from the sedimentation algorithm utilized in the bulk scheme described below since here, the parameters used in the power-law relationships are a function of particle size whereas the parameters are fixed in the bulk model (as in nearly all bulk schemes). The increased complexity of the bin microphysics model requires a more physically consistent algorithm for representing the sedimentation process.

\subsection{Bulk microphysics model}

We utilize the Morrison et al. (2009) two-moment bulk microphysics scheme in the present study with modifications to explicitly analyze the effects of the saturation adjustment scheme. In order to include the effect of aerosols on droplet number concentration during the activation process, a binned aerosol size distribution is included in the model. The method for calculating the activation of aerosol particles and regenerating aerosols upon the evaporation of cloud drops is the same as that in the bin scheme (Lebo and Seinfeld, 2011). By representing the aerosol distribution, as well as the activation/regeneration processes, in a consistent manner between the bin and bulk schemes, we reduce the number of degrees of freedom when analyzing and comparing the results for the models. Here, we discuss the three configurations of the bulk scheme:

1. Standard Model (bulk-original) - In this configuration, the bulk microphysics scheme is employed as in Morrison et al. (2009) and thus includes the calculation of saturation adjustment for condensation and evaporation of cloud drops with the addition of the aforementioned activation/regeneration scheme for a binned aerosol size distribution. This is similar to the approach for activation used for the bulk microphysics scheme tested by Lebo and Seinfeld (2011). In this approach, activation of cloud droplets is predicted using the ambient supersaturation after advection, adiabatic expansion/cooling, and subgrid-scale mixing, but before saturation adjustment (following the bulk scheme of Seifert and Beheng, 2006). Note that all of the bulk schemes including bulkoriginal include an explicit representation of ice supersaturation and vapor deposition/sublimation. Hence, for bulk-original the saturation adjustment is only applied to condensation/evaporation of liquid cloud droplets.

2. Supersaturation Forced Condensation/Evaporation and Activation (bulk-explicit) - Here, the bulk model is configured without saturation adjustment for condensation/evaporation and the activation of aerosol particles. Instead, following, e.g., Clark (1973); Reisin et al. 
(1996); Stevens et al. (1996); Harrington et al. (2000); Morrison and Grabowski (2008); Lebo and Seinfeld (2011), we express the rate of change of the water vapor surplus ( $\eta=q_{v}-q_{v, s}, q_{v}$ is the water vapor mixing ratio and $q_{v, s}$ is the saturation water vapor mixing ratio) as a function of time $(t)$ as:

$\frac{d \eta(t)}{d t}=D-G \eta(t)$

where $G$ is a function of temperature $(T)$, pressure $(P)$, droplet mass, and number concentration, i.e., the loss (gain) of water vapor due to condensation (evaporation), and $D$ represents the dynamical forcing,

$D=-\frac{1}{\rho} \nabla \cdot(\rho \eta)+\frac{d q_{s}}{d T} \frac{g}{c_{p}} w-q_{v, s} \frac{\rho g w}{P-e}$

where $\frac{d q_{s}}{d T}$ is the psychrometric term, $g$ is the acceleration due to gravity, $c_{p}$ is the specific heat of air, $w$ is vertical velocity, and $e$ is the saturation vapor pressure. In Eq. (4), the first term on the right hand side represents the advected tendency in the water vapor surplus, the second term corresponds to changes in the water vapor surplus due to adiabatic compression/expansion, and the third term represents the effect of changes in pressure on $\eta$. As in the bin microphysics scheme (Reisin et al., 1996; Harrington et al., 2000; Lebo and Seinfeld, 2011), Eq. (3) is integrated analytically over the time step, and the integrated water vapor surplus is, in turn, used to explicitly calculate condensation/evaporation. Moreover, the average water vapor surplus $\left(\eta_{a}\right)$ is used to compute droplet activation following the method used in the bin model (Lebo and Seinfeld, 2011).

3. Supersaturation Forced Condensation/Evaporation Only (bulk-cond) - In order to distinguish between the influence of the saturation adjustment scheme on aerosol effects caused by condensation/evaporation and activation separately, we include an additional configuration of the bulk model in which condensation/evaporation is computed following the algorithm described above using the predicted supersaturation over the course of the model time step. Activation is treated as in bulk-original by predicting the temperature and water vapor mixing ratio as if the saturation adjustment was used at the end of the previous time step. Thus, instead of using $\eta_{a}$ to predict the activation of aerosol particles, saturation adjustment is performed at the end of a time step, and the subsequent $T$ and $q_{v}$ are reserved for calculating the supersaturation following advection at the next time for the purposes of computing activation only. Thus, in this model configuration, activation is treated as in the bulk-original model while condensation/evaporation is treated following the method used in the bulk-explicit model configuration.
Lastly, saturation adjustment is only applied to cloud liquid water at the end of the time step, after all other processes have been calculated. Deposition of ice hydrometeors is calculated explicitly during the time step based on ice particle characteristics and the ambient supersaturation with respect to ice.

\section{Model setup and description of test cases}

The bin and bulk microphysics models described in Sect. 2 are coupled to the Weather Research and Forecasting (WRF) model Version 3.3 (Skamarock et al., 2008) as a 3-D CRM. The model is compressible and nonhydrostatic. The domain extends to $200 \times 200 \mathrm{~km}^{2}$ in the horizontal and $24 \mathrm{~km}$ in the vertical. The grid spacing is $1 \mathrm{~km}$ in the horizontal and $343 \mathrm{~m}$ in the vertical (i.e., 70 levels). Unlike the case of stratocumulus and shallow cumulus, for which high vertical resolution (i.e., grid spacing of order $10 \mathrm{~m}$ ) is required to resolve peak supersaturations near cloud base (e.g., Stevens et al., 2005), vertical velocities are large and tend to increase substantially in strength above cloud base in supercell storms. Thus, using high vertical resolution to resolve the detailed supersaturation structure near cloud base is less likely to be important when simulating these storms. The model time step is chosen to be $5 \mathrm{~s}$ to ensure numerical stability, and the duration of the simulations is $2 \mathrm{~h}$. Rayleigh dampening is applied in the top $5 \mathrm{~km}$ of the grid, and open lateral boundary conditions are employed. For the purposes of this idealized study, we exclude radiation, surface fluxes, and Coriolis force. All scalars are advected in the horizontal and vertical using 5th and 3rd order positive-definite advection schemes, respectively.

The WRF model is initialized with a thermodynamic profile conducive to convective development, following Weisman and Klemp $(1982,1984)$, containing a convective available potential energy (CAPE) of $2160 \mathrm{~J} \mathrm{~kg}^{-1}$ (Fig. 1). We use the quarter-circle shear wind profile of Morrison and Milbrandt (2011) and Morrison (2012). Convection is initiated using a thermal perturbation $\left(\theta^{\prime}\right)$ of $3 \mathrm{~K}$ with a height of $1.5 \mathrm{~km}$ and a radius of $10 \mathrm{~km}$ that varies as a function of the cosine of the distance from the center of the bubble. This method for initializing convection is analogous to that used in many recent studies (e.g., Fan et al., 2009; Khain and Lynn, 2009; Lebo and Seinfeld, 2011). In order to assess the effects of an increase in aerosol loading with the bin and bulk models, we perform simulations with $\mathrm{CCN}$ number concentrations $\left(N_{\mathrm{a}}\right)$ of 100,250 , and $750 \mathrm{~cm}^{-3}$, representing "Clean", "Semi-Polluted", and "Polluted" environments. Aerosols are assumed to be ammonium sulfate and completely soluble. While the latter may be an oversimplification of the ambient aerosol chemistry, it is important to remember that the focus of this study is the effect of a physical change in the number concentration and not the effect of aerosol chemistry. The aerosols are distributed following a lognormal distribution 
Table 1. Simulation descriptions.

\begin{tabular}{|c|c|c|}
\hline Category & Name & Description \\
\hline \multirow[t]{3}{*}{ Microphysics Scheme } & Explicit & $\begin{array}{l}\text { Bulk microphysics model incorporating an explicit representa- } \\
\text { tion of the supersaturation evolution within a time step, includ- } \\
\text { ing effects on both condensation/evaporation and activation } \\
\text { Bulk microphysics model incorporating an explicit representa- } \\
\text { tion of the evolution of the supersaturation within a time step, } \\
\text { including effects on only condensation/evaporation. Activation } \\
\text { is computed using the saturation adjusted temperature and water } \\
\text { vapor mixing ratios. }\end{array}$ \\
\hline & Original & Bulk microphysics model with saturation adjustment \\
\hline & Bin & Bin microphysics model \\
\hline \multirow{7}{*}{ Sensitivities } & Base & Control case (i.e., no perturbations) \\
\hline & $\operatorname{delT} 25$ & Maximum $\theta^{\prime}$ in the thermal bubble reduced to $2.5 \mathrm{~K}$ \\
\hline & delT35 & Maximum $\theta^{\prime}$ in the thermal bubble increased to $3.5 \mathrm{~K}$ \\
\hline & lowshear & Vertical wind shear increased by $5 \%$ in the lowest $7.5 \mathrm{~km}$ \\
\hline & highshear & Vertical wind shear decreased by $5 \%$ in the lowest $7.5 \mathrm{~km}$ \\
\hline & lowRH & $\mathrm{RH}$ reduced by $2 \%$ \\
\hline & highRH & RH increased by $2 \%$ \\
\hline \multirow{3}{*}{ Pollution } & Clean & $N_{\mathrm{a}}=100 \mathrm{~cm}^{-3}$ \\
\hline & Semi-Polluted & $N_{\mathrm{a}}=250 \mathrm{~cm}^{-3}$ \\
\hline & Polluted & $N_{\mathrm{a}}=750 \mathrm{~cm}^{-3}$ \\
\hline
\end{tabular}

Table 2. Summary of results for the suite of model configurations described in Table 1 . The change in precipitation $(\Delta P)$, convective mass flux $(\Delta M F)$, and average potential temperature within the cold pool $\left(\Delta \theta^{\prime}\right)$ are shown for "Polluted" minus "Clean" conditions. Statistics for $\Delta M F$ are computed by averaging between $t=30$ and $120 \mathrm{~min}$ and between $z=2.1$ and $9.1 \mathrm{~km}$. For $\Delta \theta^{\prime}$ and $\Delta P$ the results are shown only for $t=120 \mathrm{~min}$. The percent change relative to the "Clean" case is shown in parentheses. Within each column, the top values correspond to the low perturbation sensitivity simulations while the bottom values correspond to the high perturbation simulations (i.e., the delT25 run is above the delT35 run, etc.).

\begin{tabular}{|c|c|c|c|c|c|c|c|c|c|c|c|c|}
\hline \multirow{2}{*}{ Model Configuration } & \multicolumn{4}{|c|}{$\Delta P[0.01 \mathrm{~mm}]$} & \multicolumn{4}{|c|}{$\Delta M F\left[0.001 \mathrm{~kg} \mathrm{~m}^{-2} \mathrm{~s}^{-1}\right]$} & \multicolumn{4}{|c|}{$\Delta \theta^{\prime}[0.1 \mathrm{~K}]$} \\
\hline & Base & delT & shear & RH & Base & delT & shear & RH & Base & delT & shear & RH \\
\hline \multirow{2}{*}{ Bulk-Explicit } & \multirow{2}{*}{$1.21(0.93)$} & $2.44(1.17)$ & $-1.86(-1.50)$ & $1.40(1.20)$ & \multirow{2}{*}{$6.31(5.09)$} & $3.75(3.18)$ & $3.05(2.52)$ & $4.47(4.06)$ & \multirow{2}{*}{$1.75(5.20)$} & $0.82(2.44)$ & $3.17(9.35)$ & $2.05(6.35)$ \\
\hline & & $-1.62(-1.18)$ & $2.51(1.85)$ & $-3.56(-2.34)$ & & $4.96(3.80)$ & $6.13(4.74)$ & $4.79(3.40)$ & & $2.71(8.16)$ & $0.29(0.87)$ & $1.39(4.02)$ \\
\hline \multirow{2}{*}{ Bulk-Cond } & \multirow{2}{*}{$-0.53(-0.41)$} & $1.63(1.34)$ & $-2.42(-1.95)$ & $-1.14(-1.00)$ & \multirow{2}{*}{$4.50(3.50)$} & $3.55(2.99)$ & $2.69(2.22)$ & $3.50(3.14)$ & \multirow{2}{*}{$2.76(8.25)$} & $-0.71(-2.16)$ & $3.62(10.8)$ & 3.61 (11.1) \\
\hline & & $-1.46(-1.06)$ & $0.51(0.38)$ & $-3.33(-2.21)$ & & $3.56(2.70)$ & $6.42(4.94)$ & $2.30(1.61)$ & & $2.23(6.70)$ & $1.07(3.26)$ & $2.21(6.35)$ \\
\hline \multirow{2}{*}{ Bulk-Original } & \multirow{2}{*}{$2.77(2.50)$} & $1.59(1.52)$ & $1.74(1.65)$ & $3.67(3.71)$ & \multirow{2}{*}{$-4.93(-3.50)$} & $-4.25(-3.17)$ & $-4.86(-3.62)$ & $-2.40(-1.90)$ & \multirow{2}{*}{$4.67(12.0)$} & $2.46(6.54)$ & $4.30(10.0)$ & $3.33(9.13)$ \\
\hline & & $3.25(2.81)$ & $2.25(1.92)$ & $0.17(0.13)$ & & $-3.93(-2.73)$ & $-2.60(-1.75)$ & $-5.72(-3.64)$ & & $4.28(10.9)$ & $2.43(6.52)$ & $5.38(13.1)$ \\
\hline \multirow{2}{*}{ Bin } & \multirow{2}{*}{$22.2(17.5)$} & $28.9(23.6)$ & - & - & \multirow{2}{*}{$5.50(4.73)$} & $7.04(6.43)$ & - & - & \multirow{2}{*}{$0.68(1.98)$} & $-0.79(-2.36)$ & - & - \\
\hline & & $22.5(16.8)$ & - & - & & $6.51(5.40)$ & - & - & & $1.2(3.90)$ & - & - \\
\hline
\end{tabular}

with a geometric mean diameter $\left(D_{\mathrm{g}}\right)$ of $0.1 \mu \mathrm{m}$ and a standard deviation $\left(\sigma_{\mathrm{g}}\right)$ of 1.8 (Lebo and Seinfeld, 2011).

We assess the robustness of the simulated results by performing an additional set of 6 simulations by both increasing and decreasing the perturbation in the potential temperature $\left(\theta^{\prime}\right)$ within the bubble $( \pm 0.5 \mathrm{~K})$, wind shear $( \pm 5 \%)$, and the ambient relative humidity $(\mathrm{RH}, \pm 2 \%)$. The variables are only perturbed individually. It is important to note that the additional simulations serve as a test for robustness to small perturbations (following Morrison, 2012) and are not intended to study aerosol-effects on deep convective clouds occurring under significantly different environmental conditions. Details of the suite of simulations performed are summarized in Table 1. Owing to the extreme computational expense required to perform bin microphysics simulations with the chosen domain size and grid spacing, the perturbed simulations with the bin model are restricted to only perturbing the strength of the initial thermal bubble. Thus, we present the results from a set of 72 simulations.

\section{Results and discussion}

Results of the suite of model simulations described in Table 1 are discussed here, focusing on various aspects of the storm response to an increase in aerosol loading. Namely, we discuss sensitivity of aerosol impacts on the cumulative precipitation, convective dynamics, and cold pool strength to use of saturation adjustment. 


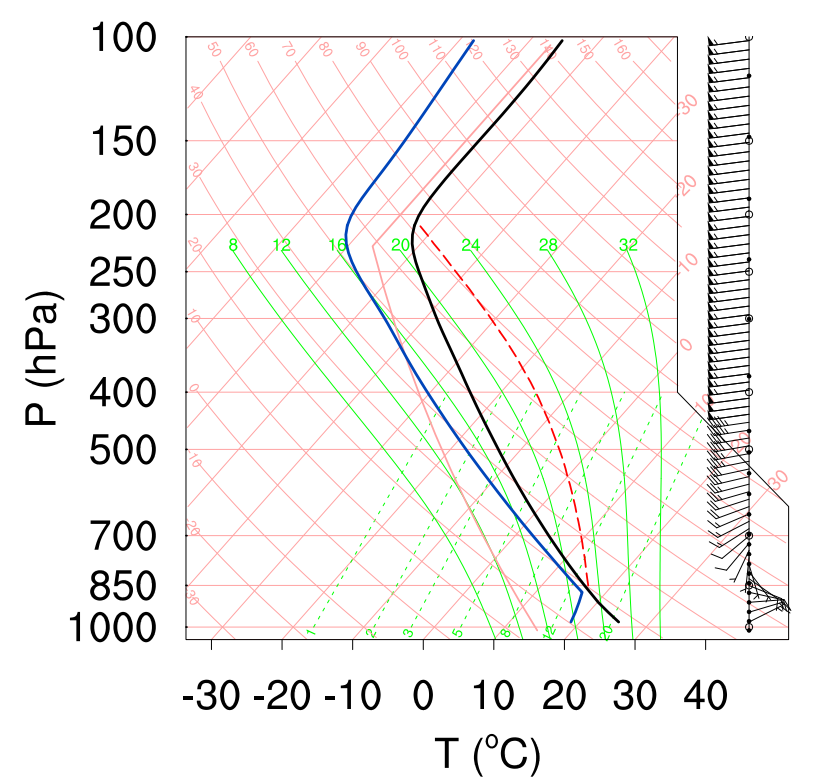

Fig. 1. Skew-T log-P diagram for the simulations with baseline initial conditions. Temperature $(T$, black) and dew point temperature $\left(T_{d}\right.$, blue) are shown.

\subsection{Precipitation response to increased aerosol loading}

Figure 2 demonstrates the different responses to an increase in aerosol loading for each model configuration. Detailed statistics for all "Clean" and "Polluted" simulations are presented in Table 2. The data are shown only for these two cases since the qualitative changes between "Clean" and "Semi-Polluted" are similar to those between "Clean"" and "Polluted" scenarios. On the whole, the bulk-original model predicts the least domain-average precipitation, regardless of the aerosol number concentration. All but the bulk-cond model configuration predict an increase in the domain-averaged precipitation at $120 \mathrm{~min}$ in polluted compared to clean conditions, although the magnitude of the increase is much larger using the bin model compared to any of the bulk configurations. It should be noted, from Table 2, that the sign of the change in precipitation for the bulk-cond and bulk-explicit model configurations are not robust to the sensitivity perturbations.

From Fig. 2, we see that there is little difference in domainaverage cumulative precipitation between the bulk-explicit and bulk-cond simulations. In other words, for this case, Fig. 2 suggests that the surface precipitation is insensitive to the method used to compute the supersaturation for droplet activation. This is understandable, since within the convective core the supersaturation is relatively high, such that most, if not all, aerosol particles will activate regardless of the integrated supersaturation (bulk-explicit) or the pseudosaturation adjusted temperature and water vapor mixing ratio (bulk-cond). Changes in other quantities (convective mass

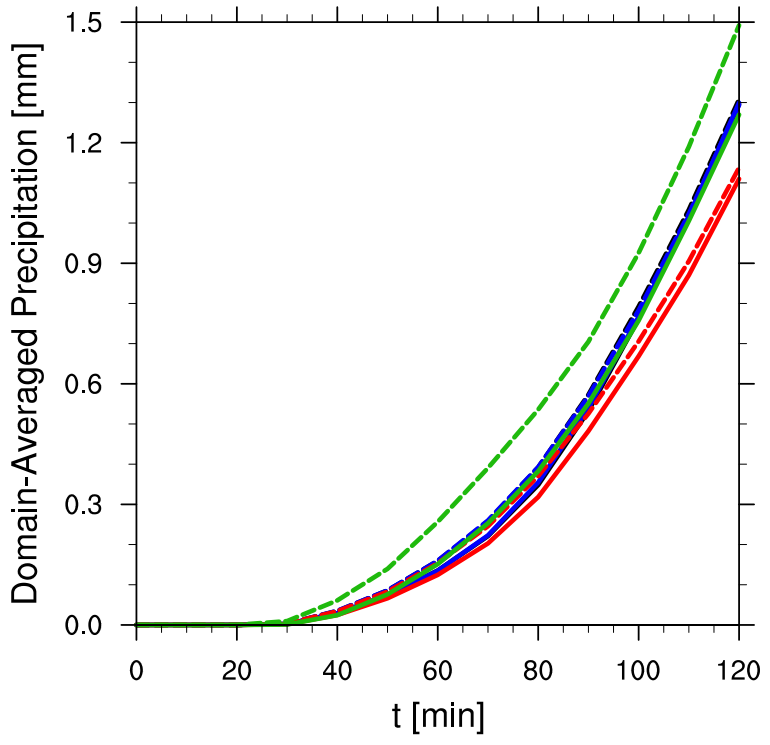

Fig. 2. Domain-average cumulative precipitation. Depicted here are the "Clean" (solid) and "Polluted" (dashed) aerosol scenarios for simulations using the baseline initial conditions. All four model configurations are presented, i.e., bin (green), bulk-explicit (black), bulk-cond (blue), and bulk-original (red).

flux, cold pool perturbation $\theta$ ) are also similar between bulkexplicit and bulk-cond, as described later.

Figure 2 and Table 2 suggest that the precipitation response to an increase in aerosol loading is much larger using the bin microphysics model than in any of the bulk configurations. In Fig. 3, contour plots of the difference in cumulative precipitation ( $\Delta P$, "Polluted" minus "Clean") show that for all bulk model configurations, there is an enhancement in precipitation in the left (north) moving storm and a shift in precipitation toward the south in the center of the storm as it splits. While the precipitation pattern does change in the right-moving storm, the differences are smaller compared to the changes in the left-moving storm. Moreover, Fig. $3 \mathrm{~d}$ shows that the increase in precipitation with increased aerosol loading for the bin model (Fig. 2) is the result of a large increase in precipitation in the left-moving storm. The large increase, caused by more intense rainfall in this area, is reduced for the domain-wide average because the precipitation decreases in the right-moving cell. The following question then arises: Why is the precipitation much more sensitive to an aerosol perturbation in the bin model compared with the bulk model configurations?

In Fig. 4, evolution of the domain-averaged vertical profile of the total water mixing ratio $\left(q_{\text {tot }}\right)$ within the convective core is depicted for the bin (green), bulk-explicit (black), and bulk-original (red) model configurations (note that the $x$-axes are different). Here, the conditional averaging comes from dividing the sum of $q_{\text {tot }}$ for all points at a given level in which $z \geq 2 \mathrm{~m} \mathrm{~s}^{-1}$ by the horizontal domain area. It is 


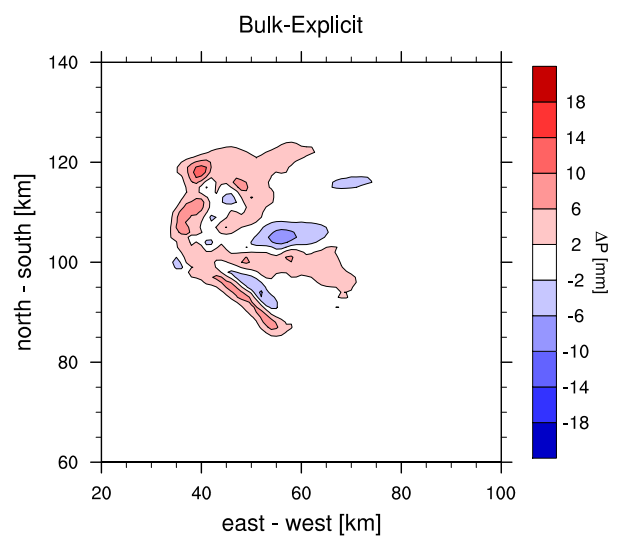

(a)

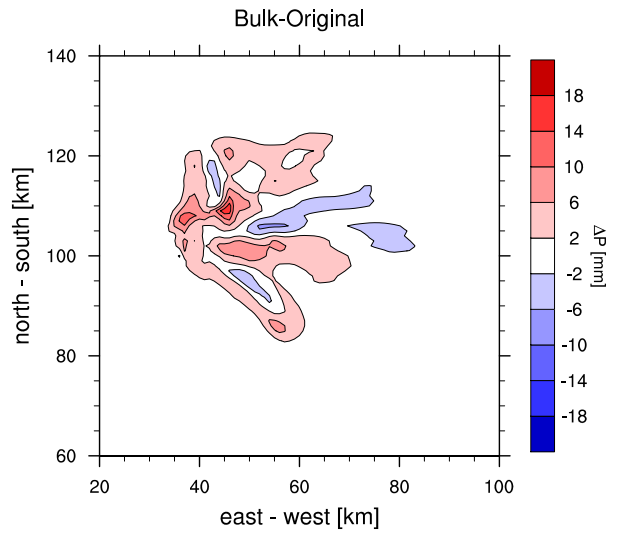

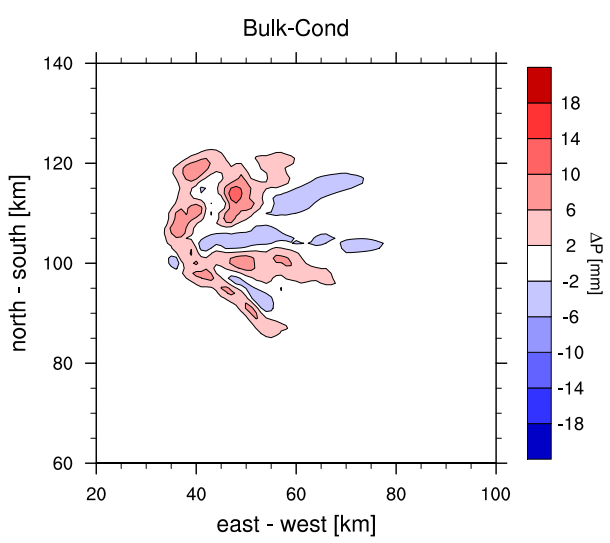

(b)

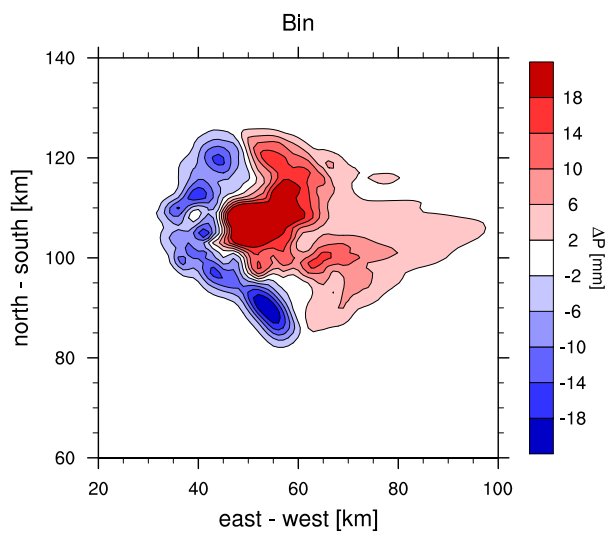

Fig. 3. Contour plots of the change in cumulative precipitation ( $\Delta P$, "Polluted" minus "Clean") at 90 min for all model configurations and baseline initial conditions. Precipitation is given in $\mathrm{mm}$. Note that only the portion of the domain in which precipitation has accumulated is shown. Here, red implies an increase in precipitation with increased aerosol loading and blue a decrease.

important to note that by averaging in this manner, we include both the effect of an increase in the magnitude of $q_{\text {tot }}$ within the core, as well as the effect of increasing the size of the convective core on $q_{\text {tot }}$ due to an increase in aerosol loading. Changes in amount of condensate aloft are further illustrated by timeseries of the difference ("Polluted" minus "Pristine") in domain-mean total condensed water path (vertically-integrated) in Fig. 5. After $30 \mathrm{~min}$, both the bin and bulk-explicit models predict an increase in $q_{\text {tot }}$ for "Polluted" compared to "Clean" throughout most of the column while the bulk-original model predicts a decrease (Fig. 4). However, the increase in $q_{\text {tot }}$ using the bin model is much larger than that predicted by the bulk-explicit model. The increased condensate then precipitates out of the column and total condensed water path decreases after about $70 \mathrm{~min}$ for the bin model while the bulk-explicit model demonstrates a steady increase in the total water path for "Polluted" relative to "Clean" (Fig. 5). This suggests that differences in the representation of ice growth processes and sedimentation can lead to potentially significant differences in the response of surface precipitation to aerosol loading in the bulk and bin model configurations. Large differences in graupel/hail growth between the bulk and bin models are suggested by Fig. 6, which shows the relative change in mean graupel diameter for "Polluted" relative to "Clean" using the bulkexplicit, bulk-original, and bin models. (Note that for completeness, profiles up to $15 \mathrm{~km}$ are shown. However, in some instances, especially in the bulk-explicit model configuration above $12 \mathrm{~km}$, large values of the relative change in mean graupel diameter are rather large due to the small sample of grid points with graupel at the high levels.) Throughout most of the troposphere, a clear increase in graupel size (due to an increase in riming) is predicted, regardless of the model configuration. However, the increase, especially in the mid to upper levels of the cloud, is much larger for the simulations using bin microphysics compared with the bulk model configurations. The large increase in graupel mean size leads to an increase in graupel sedimentation, melting, and surface precipitation for the bin model, consistent with the decrease in total condensed water path in "Polluted" relative to "Clean" after about $40 \mathrm{~min}$ (Fig. 5). This decrease in total water path with the bin model is primarily associated with ice condensate (mainly graupel) above $\sim 6 \mathrm{~km}$ (Fig. 4). The large increase in condensate aloft in "Polluted" compared to "Clean" 

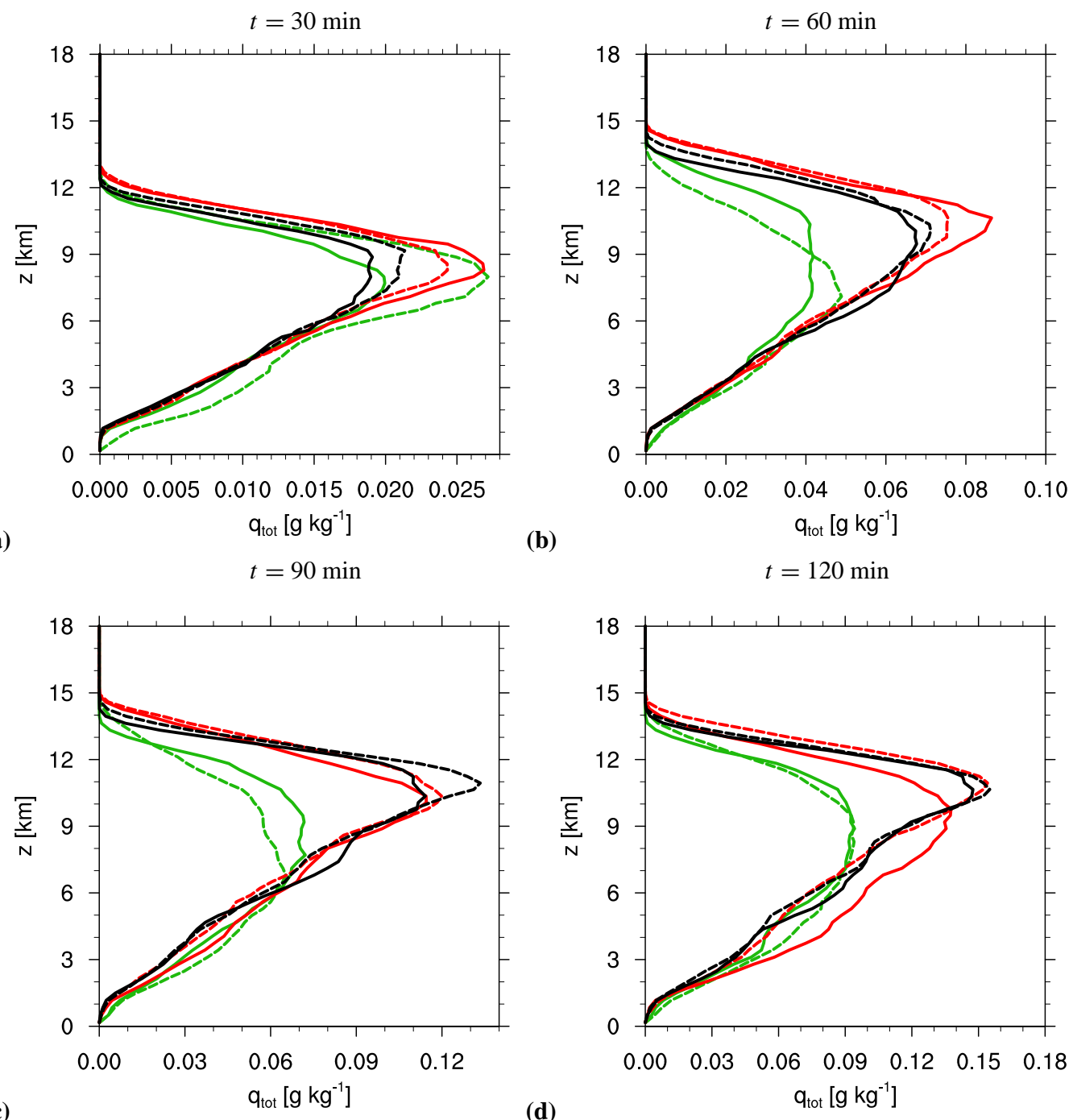

Fig. 4. Conditionally-averaged total condensate mixing ratios $\left(q_{\text {tot }}\right)$ at $30 \mathrm{~min}(\mathbf{a}), 60 \mathrm{~min}(\mathbf{b}), 90 \mathrm{~min}(\mathbf{c})$, and $120 \mathrm{~min}$ (d) are depicted for the bin (green), bulk-explicit (black), and bulk-original (red) model configurations. Here, the sum of $q_{\text {tot }}$ at each level for all points in which $w \geq 2 \mathrm{~m} \mathrm{~s}^{-1}$ is computed and divided by the horizontal domain size to calculate the conditional average. Shown here are the "Clean" (solid) and "Polluted" (dashed) aerosol scenarios. Note that the $x$-axes are different so as to clearly represent the change in $q_{\text {tot }}$ between aerosol scenarios and not to distinguish between the changes in $q_{\text {tot }}$ between different times.

before 40 min simulated by the bin model is ultimately removed by sedimentation, explaining the increase in surface precipitation. Thus, large differences in the response of surface precipitation between the bin and bulk models appear to be related to the treatment of graupel growth and sedimentation. In contrast, the use of saturation adjustment instead of explicit supersaturation evolution and condensation calculations has little impact on the surface precipitation response. However, as shown below, other differences in the simulated storms between the bulk and bin models are reduced by including the explicit representation of the supersaturation evolution in the bulk-explicit model configuration.

\subsection{Sensitivity of aerosol effects on convective dynamics to saturation adjustment}

Convective mass flux is analyzed for the suite of bin and bulk simulations. As mentioned above, the changes shown for "Clean" to "Polluted" conditions are qualitatively similar to that for "Clean" to "Semi-Polluted" conditions for all model configurations and as a result are not shown for brevity in Table 2. Here, as in Morrison (2012), the horizontallyaveraged convective updraft mass flux $(\operatorname{MF}(z))$ is computed as the product vertical velocity $(w)$ and air density $(\rho)$ for all locations in which $w \geq 2 \mathrm{~m} \mathrm{~s}^{-1}$ at a given level, divided by the area of the domain. For this analysis, $\operatorname{MF}(z)$ is averaged between $z=2.1$ and $9.1 \mathrm{~km}$ and is shown in Fig. 7. In all the 


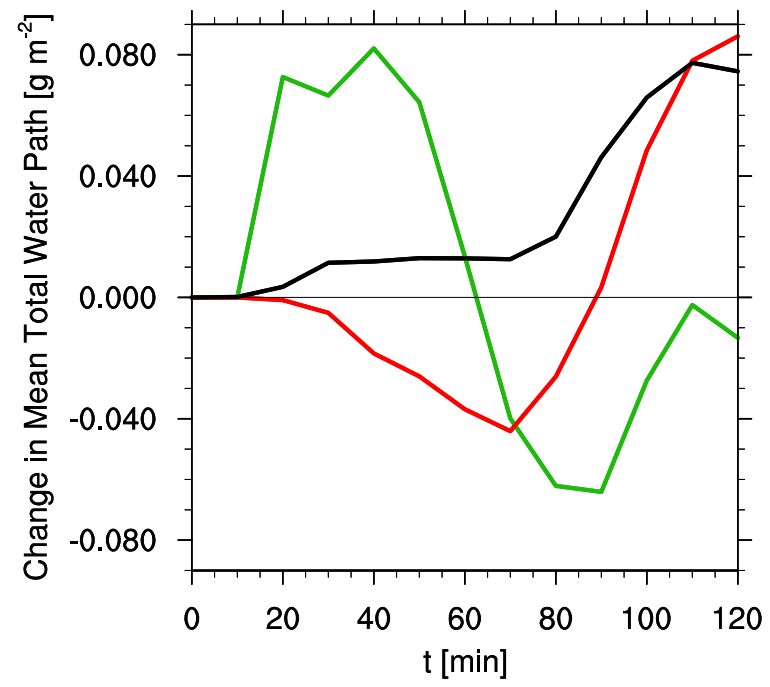

Fig. 5. Change in the domain-averaged total condensed water path ("Polluted" minus "Clean") as a function of time $(t)$ for the bin (green), bulk-explicit (black), and bulk-original (red) model configurations.

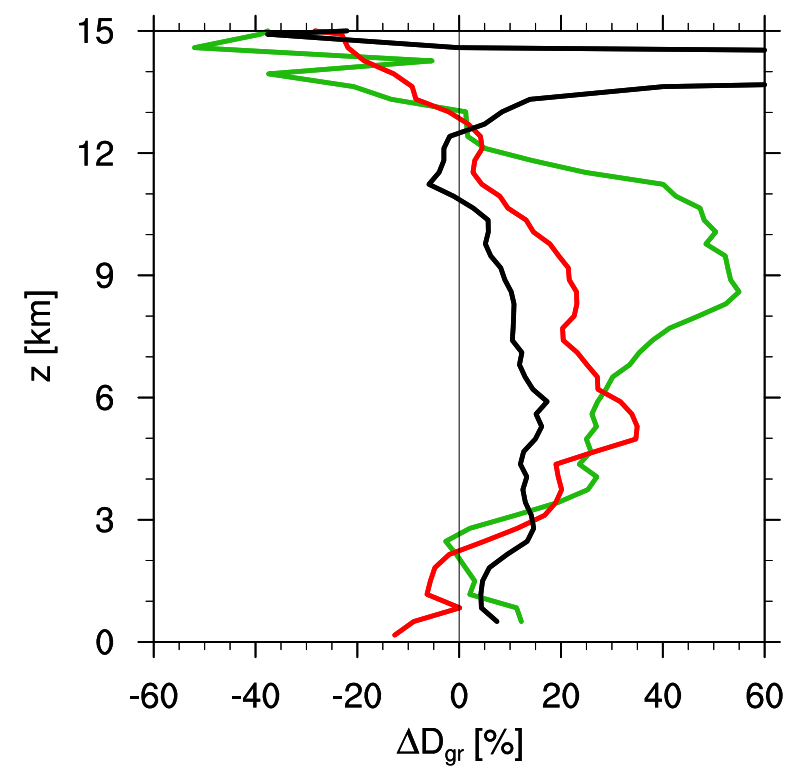

Fig. 6. Relative change in the mean graupel diameter $\left(D_{\mathrm{gr}}\right)$ due to an increase in aerosol loading ("Polluted" minus "Clean") averaged between 60 and $120 \mathrm{~min}$. Curves correspond to the bin (green), bulk-explicit (black), and bulk-original (red) model configurations.

model configurations (bulk and bin), the magnitude of the overall change in time-averaged MF between "Polluted" and "Clean" is small (less than $\sim 6 \%$ ). In Fig. 7 and Table 2, we see that MF increases by $5.09 \%$ and $3.50 \%$ for the bulkexplicit and bulk-cond model configurations, respectively,

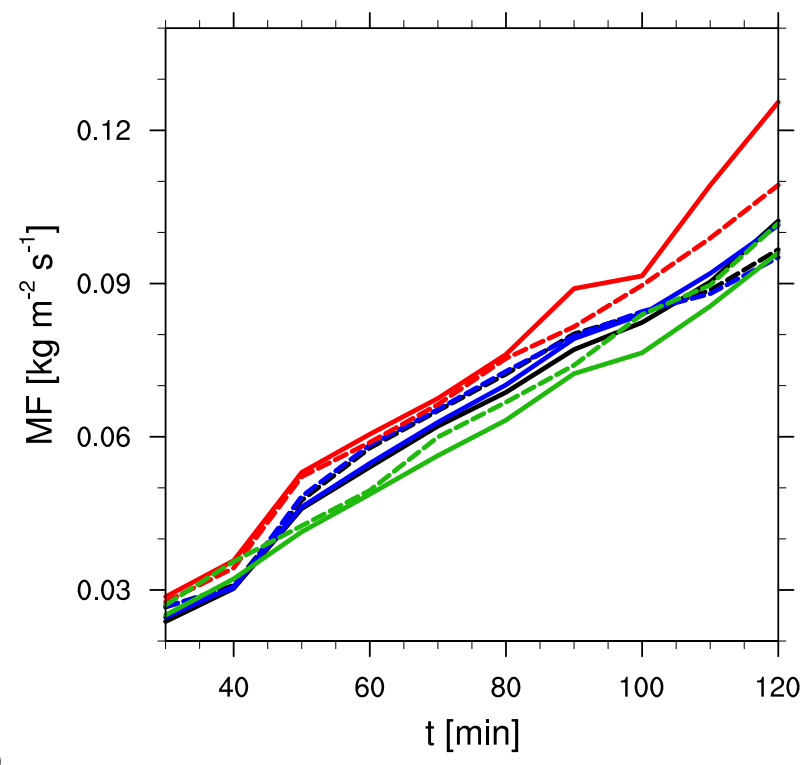

(a)

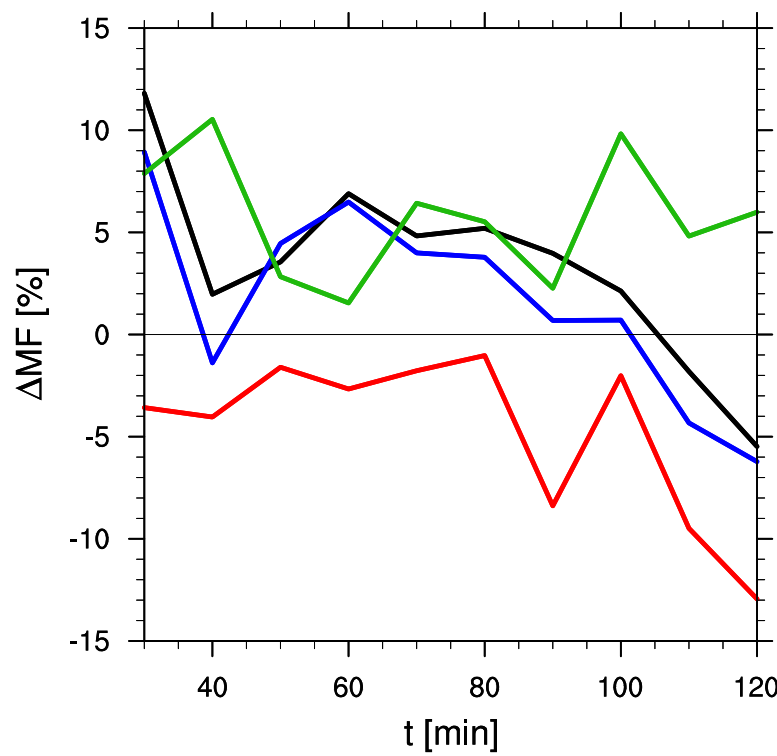

(b)

Fig. 7. (a) Vertical- and domain-average convective mass flux (MF) between 2.1 and $9.1 \mathrm{~km}$ and (b) the relative change in MF for an increase in aerosol loading. Depicted here are only the "Clean" (solid) and "Polluted" (dashed) aerosol scenarios for the base simulation setup. All four model configurations are presented, i.e., bin (green), bulk-explicit (black), bulk-cond (blue), bulk-original (red).

when averaged from 30 to $120 \mathrm{~min}$. With this in mind, we restrict the discussion to only the bulk-explicit, bulk-original, and bin model configurations (qualitatively, there are only small differences for all metrics between the bulk-explicit and bulk-cond model configurations as discussed earlier). On the other hand, the change is of opposite sign for the bulk-original configuration (in which the saturation adjustment scheme is employed). Namely, the bulk-original model 

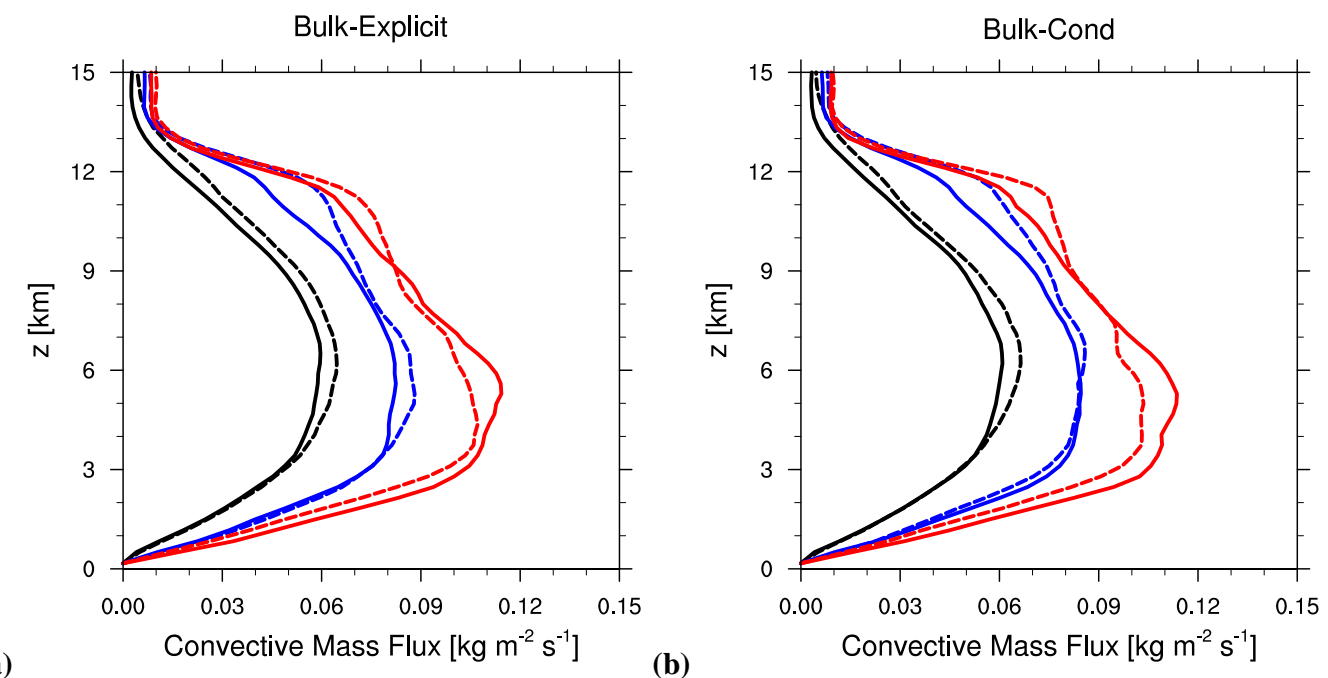

(a)

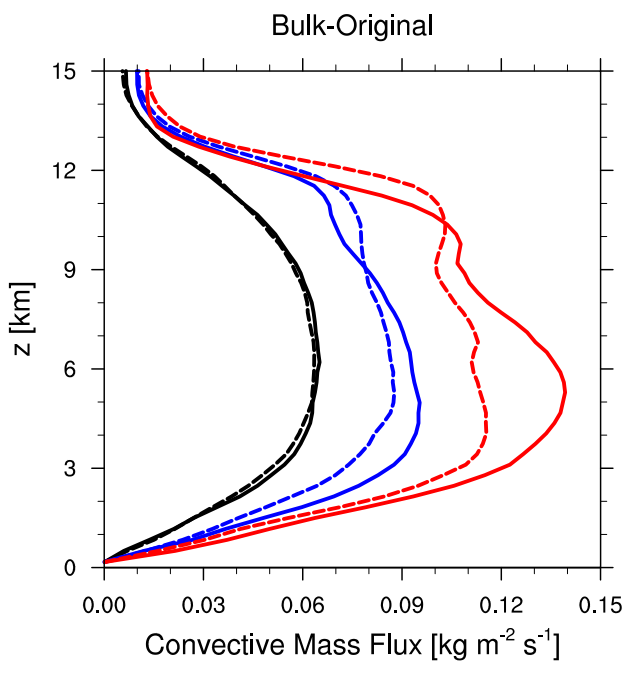

(b)

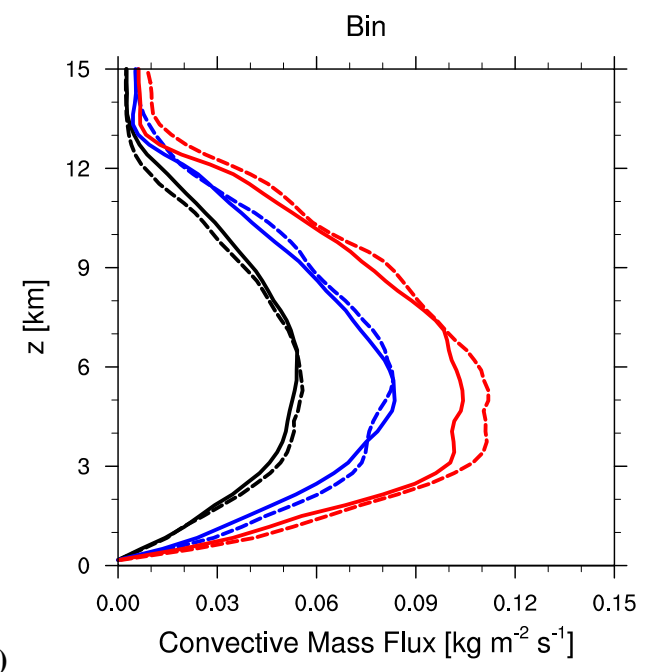

Fig. 8. Domain-average convective mass flux profiles for all four model configurations at 60 min (black), 90 min (blue), and 120 min (red). Depicted here are the "Clean" (solid) and "Polluted" (dashed) aerosol scenarios for the baseline initial conditions.

configuration predicts a small decrease in the vertically- and temporally-averaged MF by $-3.50 \%$. Figure $7 \mathrm{~b}$ shows that at all instances from 30 to $120 \mathrm{~min}$, the bulk-original model configuration predicts a decrease in vertically-averaged MF.

Differences in MF predicted by the bulk-explicit and bulkoriginal model configurations are further illustrated by vertical profiles of the horizontally-averaged MF in Fig. 8a. Here we see that the bulk-explicit model predicts an increase of MF in "Polluted" compared to "Clean" throughout the troposphere up until the end of the simulation, when there is a slight decrease at lower levels. On the other hand, Fig. 8c shows that the bulk-original model predicts a decrease throughout most of the column, especially at the end of the simulation when the decrease between 3 and $6 \mathrm{~km}$ is much larger than that predicted by the bulk-explicit model. Overall, differences in MF between "Polluted" and "Clean" with bulk-explicit are much closer to those simulated by the bin model, compared to bulk-original. Thus, while there are still quantitative differences between the bulk-explicit and bin simulations in terms of the response of MF to increased aerosol loading, bulk-explicit narrows most of the gap between the bulk-original and bin models, especially over the first 90 min of the simulations.

To understand why the change in MF with increased aerosol loading is different between the bulk-explicit and bulk-original model configurations, we turn our attention to buoyancy. The buoyancy $(B)$ equation can be defined as (Houze, 1993):

$B=g\left[\frac{T^{\star}}{T_{\mathrm{a}}}-\frac{p^{\star}}{p_{\circ}}+0.61 q_{\mathrm{v}}^{\star}-q_{\mathrm{tot}}\right]$

where $T^{\star}$ is the perturbation temperature, $p^{\star}$ is the pressure perturbation, $q_{\mathrm{v}}^{\star}$ is the perturbation water vapor mixing ratio, and $q_{\text {tot }}$ is the total condensed water mass mixing ratio 


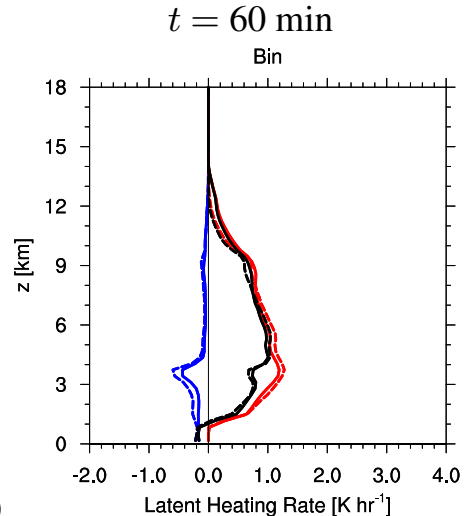

(a)

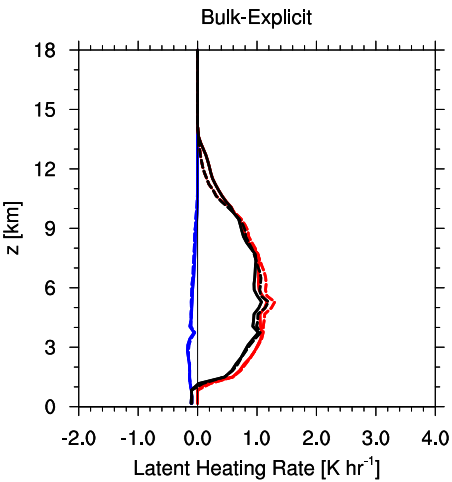

(d)

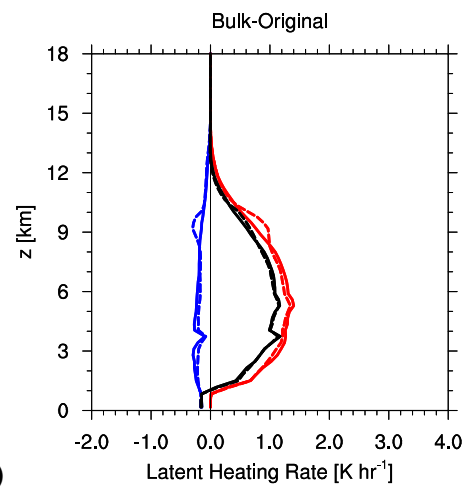

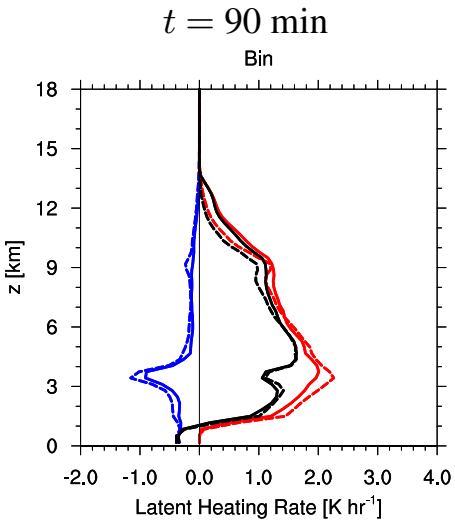

(b)

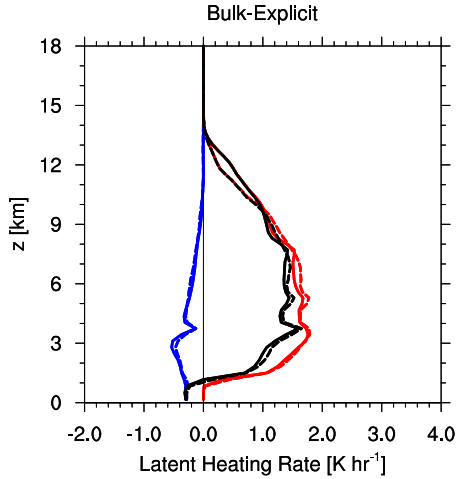

(e)

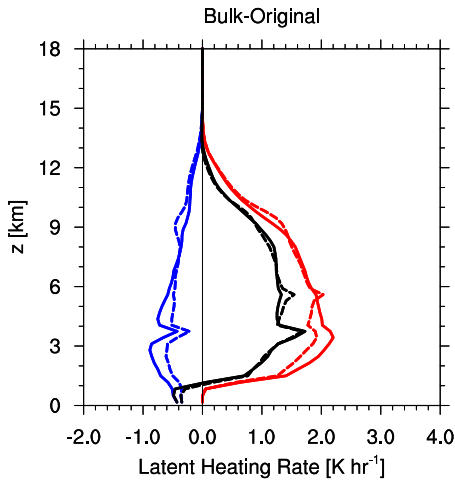

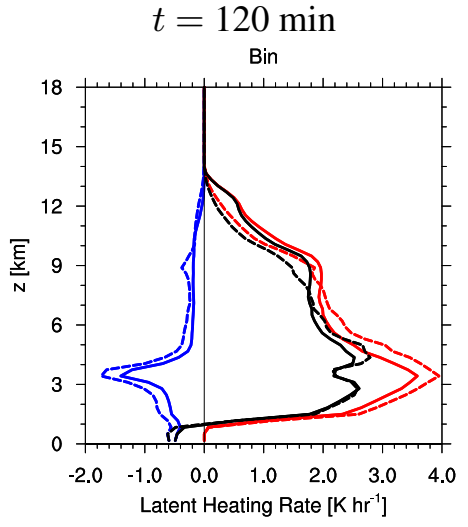

Bulk-Explicit

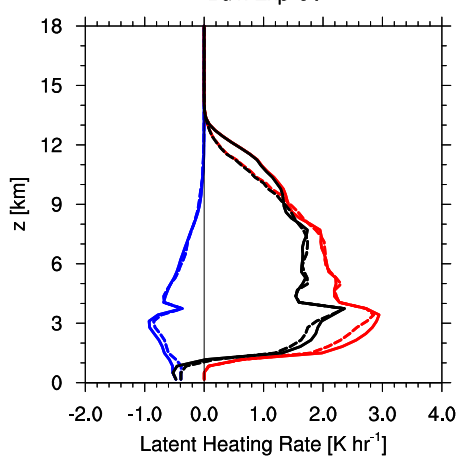

(f)

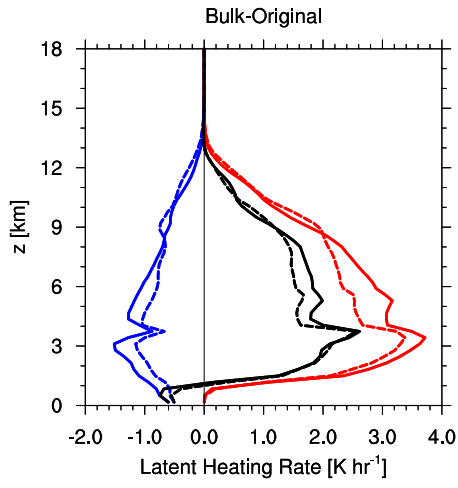

Fig. 9. Simulated latent heating rates for the bin (a-c), bulk-explicit (d-f), bulk-original (g-i) model configurations at $60 \mathrm{~min}(\mathbf{a}, \mathbf{d}, \mathbf{g}), 90 \mathrm{~min}$ (b, e, h), and $120 \mathrm{~min}(\mathbf{c}, \mathbf{f}, \mathbf{i})$. The net heating rate (black) is decomposed into the heating (red) caused by condensation, deposition, freezing, and riming and cooling (blue) caused by evaporation, sublimation, and melting. Results are shown for the "Clean" (solid) and "Polluted" (dashed) aerosol scenarios and baseline initial conditions.

(here "perturbation" refers to differences in quantities from the base state). From Eq. (5), we see that changes in aerosol loading can be linked to changes in buoyancy (and hence updraft velocity and convective mass flux), since changing the aerosol number concentration can potentially lead to changes in the total condensate (i.e., $\left.q_{\mathrm{tot}}\right)$ and latent heating $\left(T^{\star} / T_{\mathrm{a}}\right)$. As described in the Introduction, these effects counteract since, for example, an increase in condensation will act to increase the latent heating and thus increase $B$, while the corresponding increase in $q_{\text {tot }}$ will decrease $B$. This balance within deep convective systems can potentially affect the sign of the change in MF due to increased aerosol loading.

In Figs. 9a-i, latent heating rates at 60, 90, and $120 \mathrm{~min}$ are shown (first, second, and third columns, respectively). Remarkably, many of the signatures from the bin model in Figs. 9a-c are also present in the bulk-explicit simulations (Figs. 9d-f). In contrast, we see from Fig. 9g-i that there are differences in the latent heating rates at all times predicted by the bulk-explicit and bulk-original models, of which a more thorough analysis will follow below. Independent of the chosen time, Fig. 9g-i demonstrates that the bulk-original 

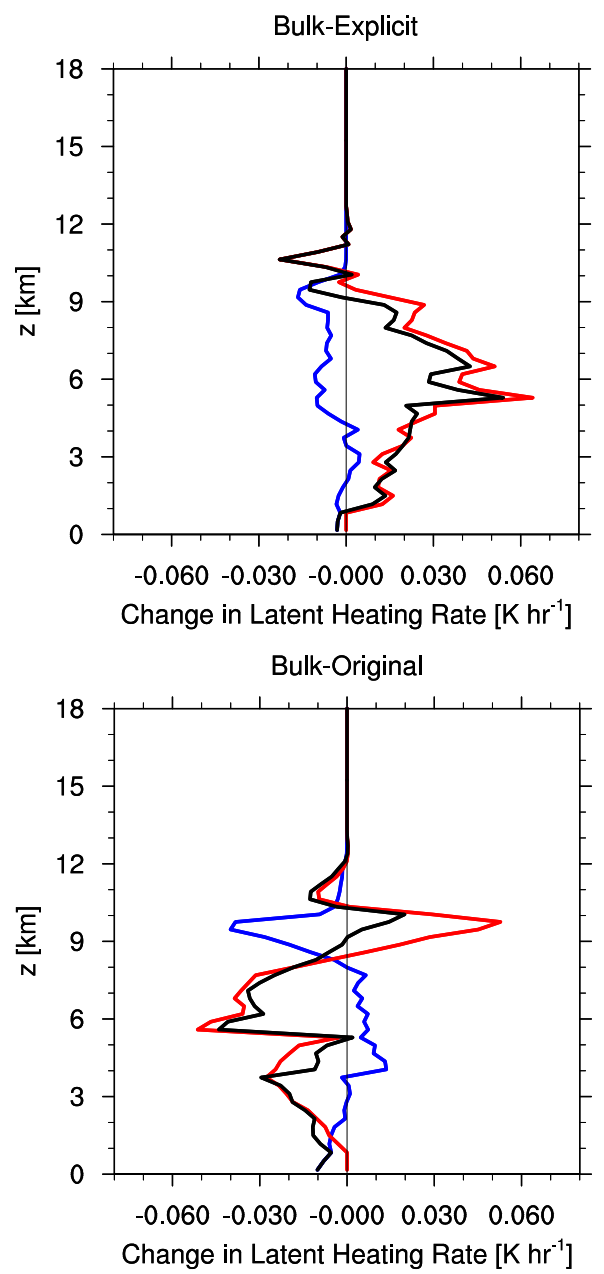

(b)

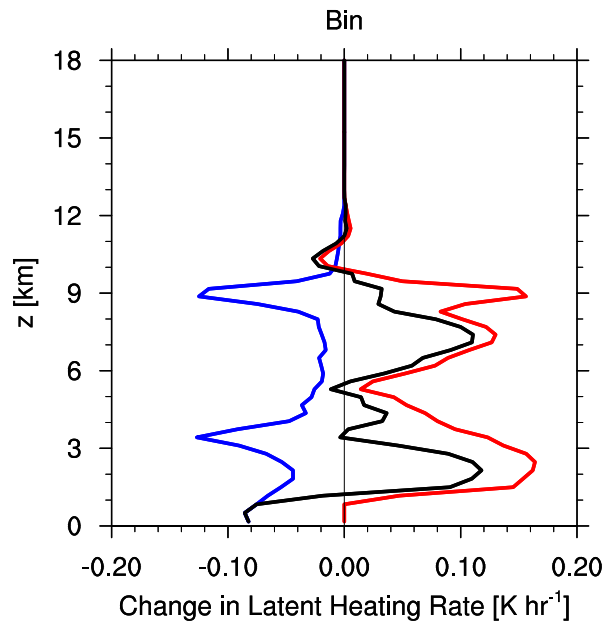

Fig. 10. Change in the latent heating rates ("Polluted" minus "Clean") for the bulk-explicit (a), bulk-original (b), and bin (c) model configurations. Shown are the changes in heating (red), cooling (blue), and net (black) heating rates for an increase in aerosol loading. Here, positive values correspond to an increase in heating (or decrease in cooling) from the "Clean" to "Polluted" scenarios. model predicts a higher latent heating rate relative to the bulk-explicit model simulations between about 3 and $9 \mathrm{~km}$ above the surface (as seen by the increase in latent heating relative to the bulk-explicit simulations, or a negative value for the changes shown). According to Eq. (5), this implies that the buoyancy, and consequently updraft mass flux, should be higher in the bulk-original model compared to the other model configurations. Consistent with this picture, MF is generally higher using the bulk-original model compared to bulk-explicit, for a given aerosol loading (Fig. 7).

If we focus our attention on the region between about 3 and $9 \mathrm{~km}$ in Fig. 9b, e, and h, we see that the bulk-explicit and bin models predict slight increases in latent heating for "Polluted" relative to "Clean" (positive buoyancy contribution, see Eq. 5). This is further demonstrated in Fig. 10 as an average over the time period from 30 to $120 \mathrm{~min}$. On the other hand, the bulk-original model predicts a decrease in heating (negative buoyancy contribution). At lower cloud altitudes, the saturation adjustment scheme produces the largest differences in the heating response between "Polluted" and "Clean" compared to that simulated by bulkexplicit (Fig. 10a and b), i.e., the sign of the change in latent heating between "Polluted" and "Clean" is different between the two models. The increase in heating aloft in "Polluted" predicted by the bulk-explicit and bin models is consistent with the increase in buoyancy and invigorated convection. However, it is important to note that there is an inherent challenge in untangling the cause and effect relationship between updraft strength (i.e., buoyancy) and latent heating. In other words, an increase in latent heating and hence buoyancy can increase updraft strength, but an increase in updraft strength can in turn increase condensation rate and latent heating. Despite this uncertainty, the bulk-original and bulk-explicit configurations allow us to unambiguously attribute changes in the response of heating and convective mass flux to the use of saturation adjustment versus explicit treatment of supersaturation.

Next, we examine differences in the latent heating and cooling rates predicted between the models in more detail (Fig. 11). A positive (negative) value for heating (red) implies that the bulk-explicit model predicts more (less) condensation/deposition/freezing/riming than the bulk-original model. For cooling (blue), a negative (positive) value implies that the bulk-explicit model predicts more (less) evaporation/sublimation/melting than the bulk-original model configuration. The difference in latent heating and cooling rates between the bulk model configurations for a given aerosol concentration is larger than the sensitivity to aerosols for a given model (compare Fig. 11 with Fig. 10). In order for the aerosol effect to be identical between the model configurations, differences between the predicted latent heating rates of each model need to be the same for all aerosol number concentrations. In other words, in Fig. 11, the dashed and solid curves should coincide. However, Fig. 11 reveals that the bulk-original model predicts more heating and cooling 
due to latent heating throughout most of the column and over the duration of the simulation compared to bulk-explicit, but the differences are much larger for "Clean" relative to "Polluted" (compare the red solid and dashed curves).

We analyze next the change in horizontally-averaged $q_{\text {tot }}$ (including only points within convective updrafts) in the context of impacts on convective dynamics. In Fig. 4, we see that for most of the column below $9 \mathrm{~km}$, bulk-original and bulkexplicit predict a decrease in $q_{\text {tot }}$ with increased aerosol loading (positive buoyancy contribution). The bin model predicts a larger decrease aloft and an increase at lower levels compared with the bulk model configurations, likely due to differences in ice growth and sedimentation as discussed earlier. However, there is not a clear relationship between changes in condensate between "Polluted" and "Clean" (Fig. 4) and changes in MF (Fig. 8). Thus, differences in condensate loading do not appear to be a primary driver of changes in convective strength between "Polluted" and "Clean" in these simulations.

With the addition of an explicit representation of supersaturation in the bulk-explicit model configuration, we are able to compare directly the predicted supersaturation fields between the bulk-explicit and bin models. Since the bulkoriginal model adjusts the supersaturation to $0 \%$ at the end of every time step, no points in the domain have supersaturation (with respect to liquid water) following calculation of the microphysical process rates. Thus, in Fig. 12 both the probability distribution function (PDF) and mean supersaturation as a function of $t$ are plotted for only the bulk-explicit and bin model configuration. Note that only positive values are shown and that all points between $z=2.1$ and $9.1 \mathrm{~km}$ and $t=30$ and 120 min are used in computing the PDFs (by excluding all data from the first 30 minutes of the simulations, we minimize the influence of the initial perturbation on the generated PDFs). The large supersaturations seen in Fig. 12 result from very large updraft velocities that are typical of supercell thunderstorms and low droplet/ice number concentrations; these values of supersaturation are confirmed by parcel model simulations (not shown). However, to date, no reliable detailed observations of in-cloud supersaturation for supercells exist. The PDFs shown in Fig. 12a show that for both the bulk-explicit and bin models, except at small supersaturations (i.e., $<2 \%$ ), there is a consistent reduction in the PDF from "Clean" (solid) to "Polluted" (dashed) conditions. Figure 12 is consistent with previously discussed results regarding latent heating and invigoration since the decrease in the supersaturation PDF in "Polluted" compared to "Pristine" corresponds to an increase in condensation and consequently an increase in latent heating aloft (Fig. 9). Figure 12b shows that the magnitude of the mean supersaturation differs between the bin and bulk-explicit model configurations, but the change in supersaturation from an increase in aerosol number concentration is quite similar. The bulk-original model cannot represent these changes in the supersaturation field resulting from increased aerosol loading, which limits its ability to
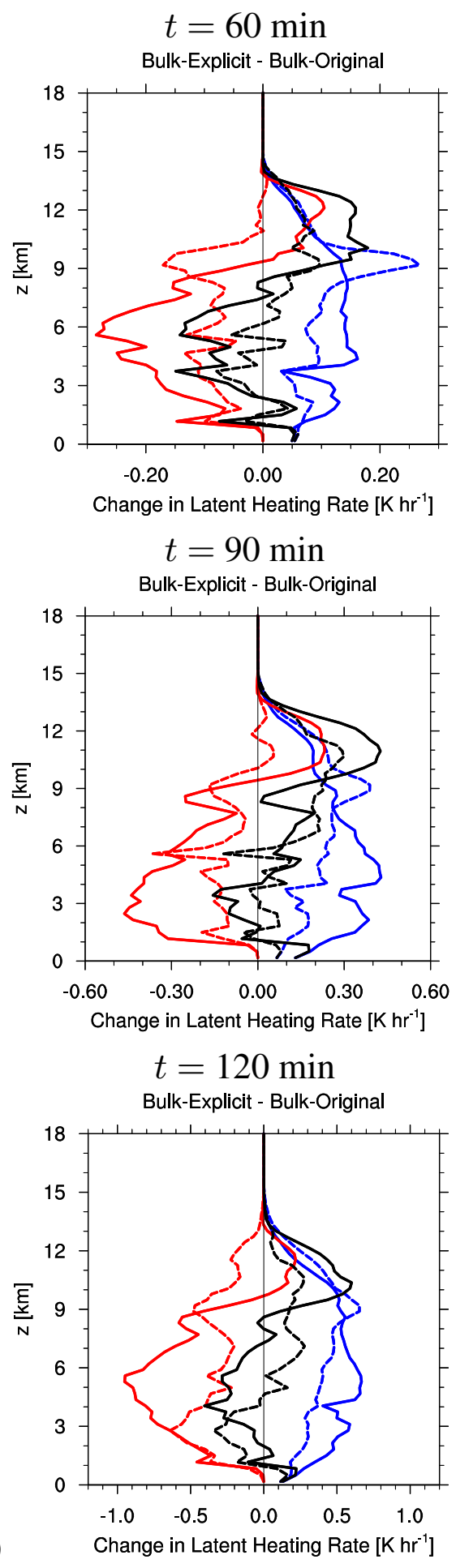

Fig. 11. Differences in the simulated latent heating rates for the bulk-explicit minus the bulk-original model configurations. Colors correspond to those used in Fig. 9. Here, a negative value for heating (positive value for cooling) corresponds to more heating (cooling) predicted by the bulk-original model than bulk-explicit. 
predict the small invigoration simulated by the bulk-explicit and bin models (Fig. 7).

In stratocumulus or shallow cumulus clouds, supersaturations often peak near or just above cloud base (Pruppacher and Klett, 1997). This is a direct result of relatively weak vertical velocities and thus a small source term in the supersaturation equation. Thus, the rapid increase in condensed liquid outweighs the supersaturation source due to rising air motion. On the other hand, in a supercell, the vertical velocity often increases substantially with height, reaching a maximum value several kilometers above cloud base. Since the vertical velocity can exceed $50-60 \mathrm{~m} \mathrm{~s}^{-1}$ within the strongest updrafts at mid- to upper-levels, there is a large supersaturation source that allows supersaturation to increase as parcels rise above cloud base. Moreover, in regions aloft where the number concentration of droplets/ice is reduced due to very efficient collection processes, the sink of water vapor due to condensation/deposition is limited. This further enhances the large increase in supersaturation above cloud base and is shown in Fig. 13 at 30 (black), 60 (blue), 90 (green), and 120 (red) min into the simulations for the bulk-explicit and bin model configurations. Only points in the domain that are supersaturated with respect to liquid are considered in Fig. 13 and only every 40th point is shown for clarity. Figure 13 clearly demonstrates that the peak in supersaturation (with respect to liquid) occurs well above cloud base. It is here that the largest errors are produced using a saturation adjustment scheme.

\subsection{Cold pool characteristics}

Much of the discussion in the literature on the potential for increased aerosol loading to result in convective invigoration has focused on changes in latent heating aloft (for a detailed conceptual overview, see Rosenfeld et al., 2008; Lebo and Seinfeld, 2011). However, increased aerosol number concentration can also lead to changes in the melting and evaporation below cloud, and thus cold pool strength. Interactions between cold pools and dynamics for supercell storms related to changes in microphysical process rates have been described in numerous recent studies (e.g., Van den Heever and Cotton, 2004; Milbrandt and Yau, 2006; Dawson II et al., 2010; James and Markowski, 2010; Morrison and Milbrandt, 2011). Tao et al. (2007) and Morrison (2012) discussed how changes in droplet number concentration caused by an increase in aerosol number concentration can lead to changes in the strength of cold pools and thus alter the convective dynamics. Morrison (2012) noted that when the change in the simulated mean cold pool perturbation temperature $\left(\Delta \theta^{\prime}\right.$, "Polluted" minus "Clean") was at least $0.2 \mathrm{~K}$ (meaning a stronger cold pool in the "Clean" aerosol scenario) there was a decrease in the convective mass flux with an increase in aerosol loading. However, when $\Delta \theta^{\prime}$ was less than $0.2 \mathrm{~K}$, the convective mass flux either increased or had a small decrease. Here, as in Morrison (2012), $\Delta \theta^{\prime}$ is defined as the dif-

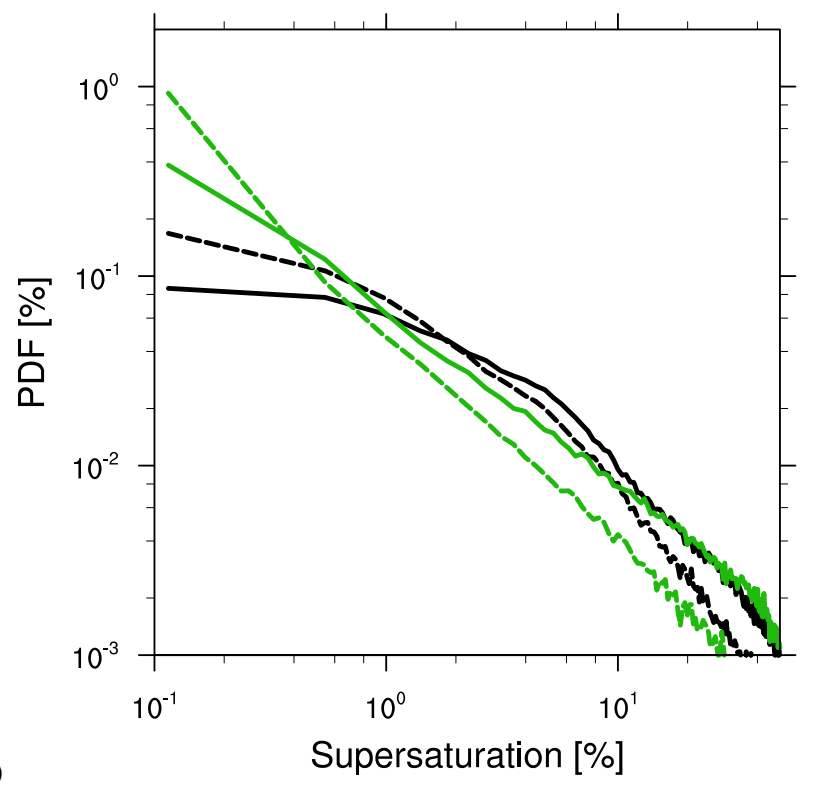

(a)

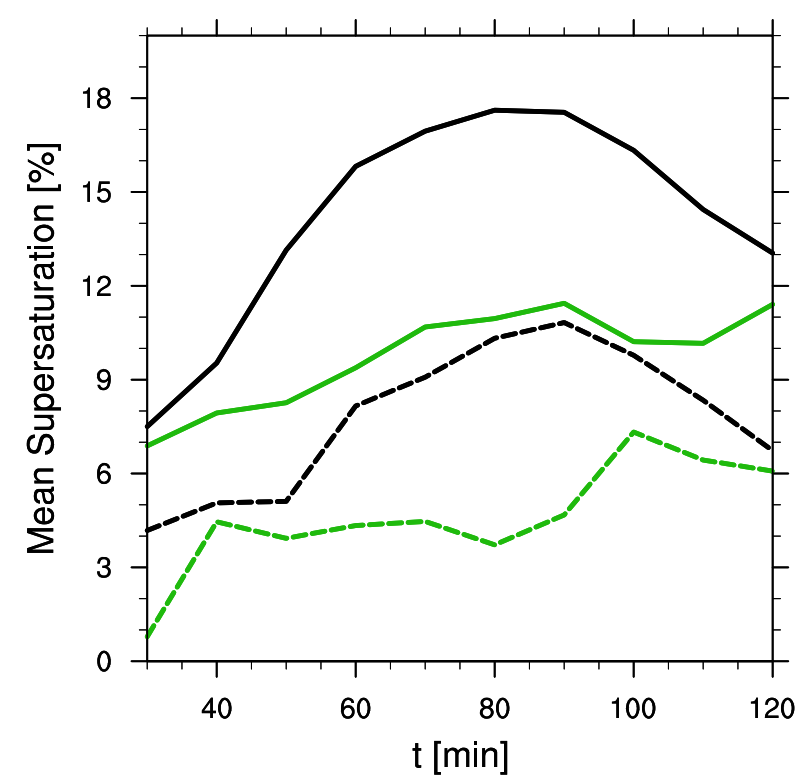

(b)

Fig. 12. (a) Probability distribution function (PDF) of the supersaturation and (b) conditionally-averaged supersaturation as a function of time. Shown are results for the bulk-explicit (black) and bin (green) model configurations for the "Clean" (solid) and "Polluted" (dash) aerosol scenarios. The PDFs are generated by analyzing all points for which $2.1 \mathrm{~km} \leq z \leq 9.1 \mathrm{~km}$ and $30 \mathrm{~min} \leq t \leq 120 \mathrm{~min}$. In (b), only points in which the supersaturation is positive are considered when computing the mean.

ference in the conditionally-averaged surface $\theta^{\prime}$ ("Polluted" minus "Clean"). The averaging is performed only within the cold pool, i.e., within the region confined by the $-2 \mathrm{~K}$ perturbation in the potential temperature field at the lowest model level. Results here are similar to Morrison (2012) as 


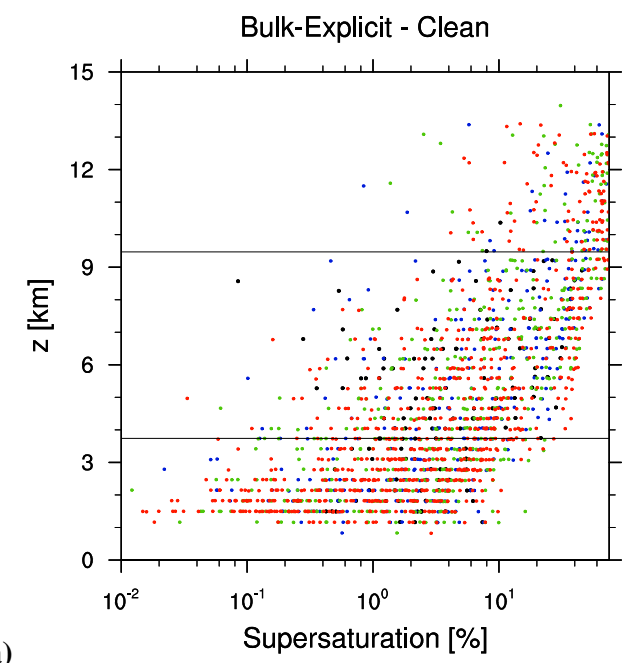

(a)

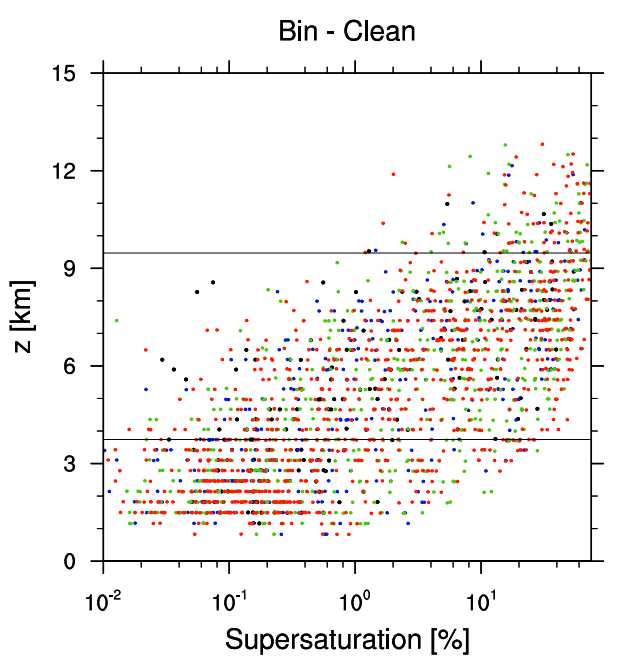

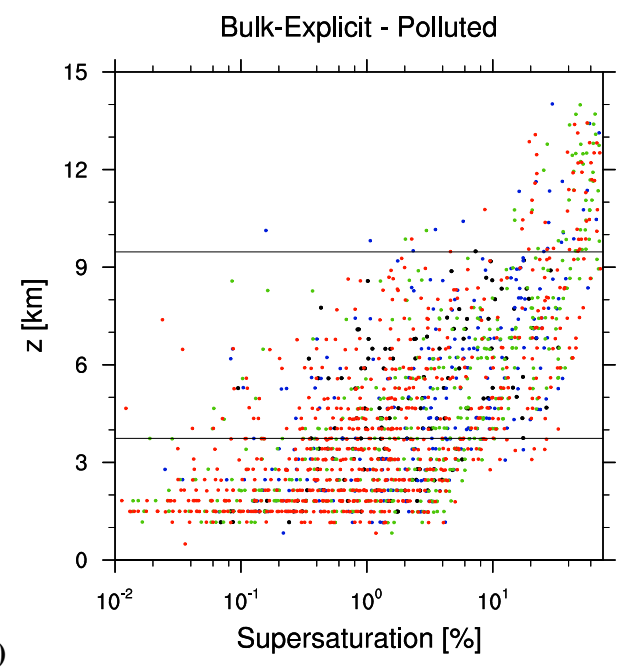

(b)

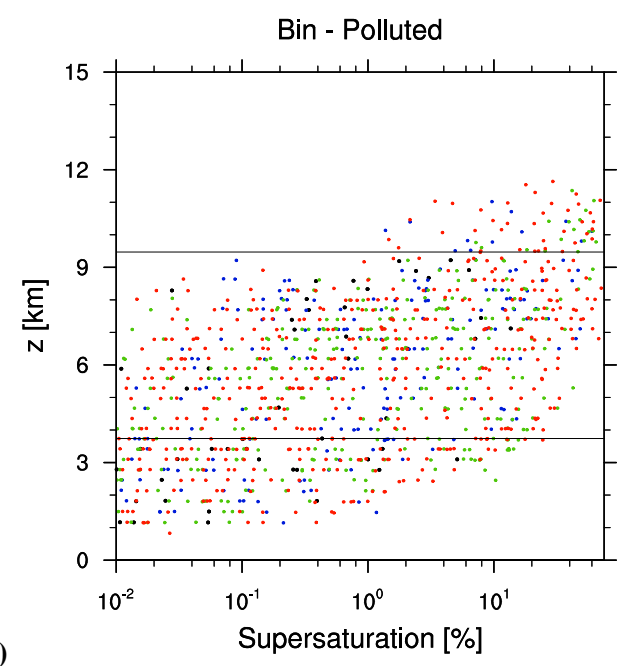

Fig. 13. Scatterplot of ambient supersaturation as a function of height and time. Due to the large data sets, only every 40th point is shown. The colors correspond to $30 \mathrm{~min}$ (black), $60 \mathrm{~min}$ (blue), $90 \mathrm{~min}$ (green), and $120 \mathrm{~min}$ (red) into the simulations for the bulk-explicit and bin model configurations. The horizontal lines at 3.4 and $10.5 \mathrm{~km}$ are shown for referencing the mean height of the $0^{\circ} \mathrm{C}$ isotherm and the height at which homogeneous freezing of droplets occurs (i.e., about $-38^{\circ} \mathrm{C}$ ).

seen in Table 2. For the bulk-original model configuration, a small weakening $(-3.5 \%)$ of the average convective mass flux occurs in "Polluted" relative to "Clean" in conjunction with a substantial weakening in the strength of the cold pool $\left(\Delta \theta^{\prime}=0.467 \mathrm{~K}\right)$, for the baseline initial conditions. On the other hand, the bulk-explicit and bin model configurations predict a much smaller weakening of the cold pool strength $(0.175$ and $0.068 \mathrm{~K}$, respectively) and a small increase in the convective mass flux (5.09 and $4.73 \%$, respectively).

In Fig. 14, interactions near the cold pool edge of the left-moving storm at $90 \mathrm{~min}$ are shown. Here, the extent of the cold pool is shown by the dashed line (demarcated by the area in which $\theta<-2 \mathrm{~K}$ ), streamlines show the flow pattern and areas of convergence/divergence at the surface, dotted contours represent the updraft velocity at $1.5 \mathrm{~km}$ (start- ing at $2 \mathrm{~m} \mathrm{~s}^{-1}$ and increasing by $2 \mathrm{~m} \mathrm{~s}^{-1}$ ), and the shaded contours depict the vertical velocity at $9.1 \mathrm{~km}$. For the bulkoriginal model configuration, Fig. 14 shows that the area of low-level convergence is elongated and the resulting lowlevel vertical velocities are higher in the "Clean" scenario compared to "Polluted", consistent with Morrison (2012). A stronger cold pool in the "Clean" case, driving greater lowlevel convergence and flow of high equivalent potential temperature air into the storm along outflow boundaries, is consistent with weak invigoration of the convective mass flux at mid- and upper-levels compared to "Polluted". On the other hand, the explicit-bulk and bin model configurations depict a different situation in which there is little change in the extent of the low-level convergence zone near the cold pool boundary owing to limited change in cold pool strength 

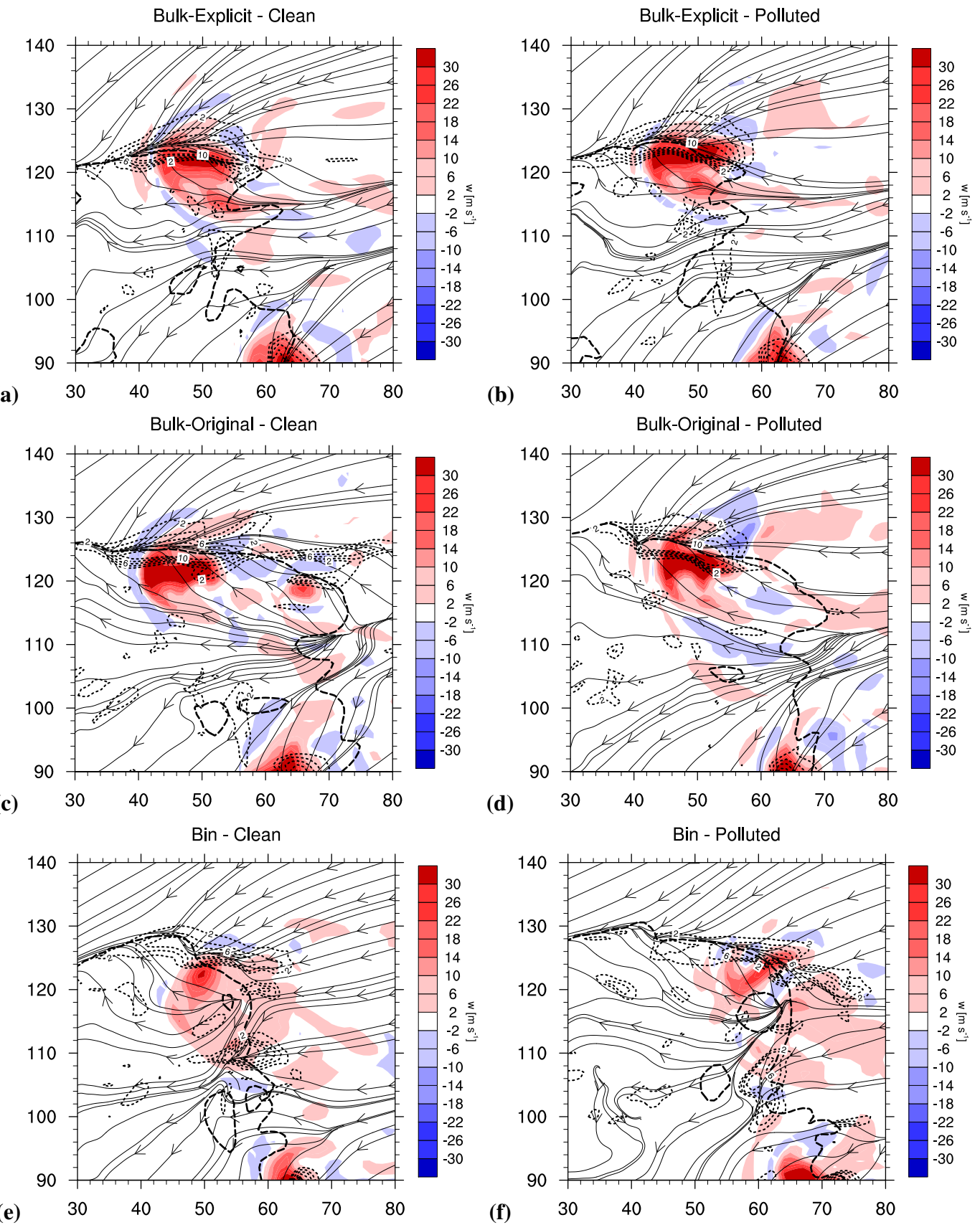

Fig. 14. Interaction between cold pool strength and convergence is shown. The cold pool boundary is demarcated by the dashed curve $\left(\theta^{\prime}<-2 \mathrm{~K}\right)$. Streamlines represent the flow at the lowest model level. Dotted contours depict the vertical velocity at $1.5 \mathrm{~km}$ starting at $2 \mathrm{~m} \mathrm{~s}^{-1}$ and stepping by $2 \mathrm{~m} \mathrm{~s}^{-1}$, while the filled contours (color bar) show the vertical velocity at $9.1 \mathrm{~km}$. The "Polluted" (b, d, f) and "Clean" (a, c, e) scenarios are shown for the bulk-explicit (a, b), bulk-original (c, d), and bin (e, f) model configurations at 90 min.

(Table 2). Consequently, in the "Polluted" scenario compared to "Clean" for the bulk-explicit and bin model configurations (Fig. 14a, b, e, f), the change in the low-level vertical velocity is quite small and it is the change in latent heat release aloft that helps drive the weak invigoration of convection (see discussion in Sect. 4.2).
Overall, these results suggest that there is more than a single pathway by which increasing the aerosol number concentration changes the overall convective dynamics, consistent with the discussion in Morrison (2012). It was suggested earlier that the bulk-explicit and bin microphysics models predict an increase in latent heating due to more deposition, 


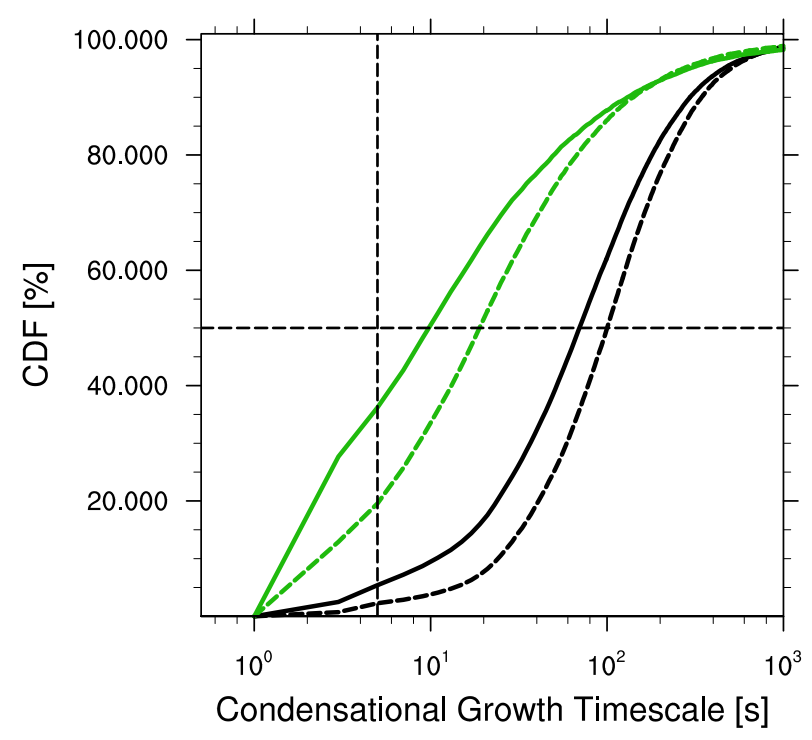

Fig. 15. Cumulative distribution function (CDF) of the condensational growth timescale. The horizontal and vertical dashed lines correspond the the 50th percentile (i.e., median of the distribution) and the model time step, respectively. Colors correspond to those used in Fig. 12. The CDF is computed by analyzing all points from 30 to $120 \mathrm{~min}$ in the simulations in which cloud water is present and the ambient air is supersaturated (i.e., condensation occurs during a time step). A lower threshold for the cloud water mixing ratio is imposed $\left(0.01 \mathrm{~g} \mathrm{~kg}^{-1}\right)$ to minimize the effect of outliers on the results.

condensation, freezing, and riming aloft when the aerosol number concentration is elevated. All else being equal, this leads to an increase in buoyancy and invigoration of the system. On the other hand, an increase in aerosol loading acts to weaken the cold pool (Table 2) which results in less low-level convergence and supply of high equivalent potential temperature air into the storm at the cold pool boundary, and hence a weakening of the convective mass flux. However, in the simulations using the bulk-explicit and bin model configurations, the small weakening in the cold pool strength appears to be more than offset by the increase in heating and buoyancy aloft. These results illustrate the importance of analyzing the system as a whole and not focusing on a single pathway by which the strength of the system can be altered in a polluted environment.

\subsection{Robustness of simulated aerosol effects}

In order to investigate the robustness of the simulated results presented herein, we performed a suite of sensitivity experiments in which the initial perturbation in the potential temperature $\left(\theta^{\prime}\right)$ within the bubble $( \pm 0.5 \mathrm{~K})$, environmental wind shear $( \pm 5 \%)$, and the ambient relative humidity $(\mathrm{RH}$, $\pm 2 \%)$ are systematically increased or decreased. The combi- nation of initial perturbations, chosen one at a time, provide a set of 6 sensitivity simulations for each aerosol scenario and model configuration. While previous works have focused on the sensitivity of aerosol effects on deep convective storms to changes in wind shear and relative humidity (Fan et al., 2009; Khain and Lynn, 2009; Lebo and Seinfeld, 2011), the purpose here is to address the robustness of the models' results to small perturbations and not to discern the effect of aerosol in different environmental conditions. For a complete review of such scenarios, see Khain et al. (2008). Data for the suite of simulations performed are presented in Table 2. For the sensitivity scenarios, the data are presented such that the top value corresponds to the low perturbation (i.e., lower maximum $\theta^{\prime}$, lower shear, and lower RH) and the bottom value corresponds to the high perturbation (i.e., higher maximum $\theta^{\prime}$, higher shear, and higher RH).

While there are quantitative differences with perturbed initial conditions in the response of cumulative surface precipitation, average convective mass flux, and cold pool strength to an increase in aerosol loading for a given model configuration, the broader conclusions are robust. In particular, key differences among the model configurations are similar with perturbed initial conditions, namely, greater weakening of cold pool strength in bulk-original compared to bulk-explicit and bin, and a weakening of average convective mass flux in bulk-original but an invigoration in bulk-explicit and bin. Furthermore, the much larger surface precipitation response to aerosols simulated by the bin model compared to all of the bulk model configurations is robust.

Nonetheless, in some cases there is a change in the sign of the storm response to aerosols when the magnitude of the response is small. For example, the bulk-explicit and bulkcond model configurations shift between small increases and decreases in precipitation for the suite of initial perturbation simulations performed (Table 2). Interestingly, although the sign of the change in precipitation, $\Delta P$, differs between some of the sensitivity experiments, the spread is comparable for all model configurations $(4.19 \%, 3.55 \%, 3.58 \%$, and $6.1 \%$ for the bulk-explicit, bulk-cond, bulk-original, and bin models, respectively). For the average convective mass flux, the bulk-explicit and bulk-cond model configurations predict a change from "Clean" to "Polluted" of between $1.61 \%$ and $5.09 \%$ across all sensitivity simulations. Similarly, the bin model predicts an increase between $4.73 \%$ and $6.43 \%$, while the bulk-original model simulates a decrease that ranges from $-1.75 \%$ to $-3.64 \%$. We note that the spread of results with perturbed initial conditions for a given model configuration is roughly comparable to previous studies investigating sensitivity aerosol effects on deep convection to model formulations (e.g., Ekman et al., 2011), and therefore may obscure analysis of such sensitivity. Thus, similar to Morrison (2012), we emphasize the importance of ensemble analysis when quantifying and generalizing aerosol effects on deep convection. 


\section{Saturation adjustment applicability}

We have demonstrated the sensitivity of simulated aerosol effects on a supercell storm to the use of a saturation adjustment scheme. It was shown that saturation adjustment in the bulk-original model leads to a small weakening of the average convective mass flux in polluted versus pristine conditions. In contrast, using an explicit calculation of the supersaturation evolution in the bulk-explicit, bulkcond, and bin models leads to a small invigoration. The key difference between these model configurations is that the bulk-original model assumes that the condensational growth timescale is no larger than the model time step (i.e., $5 \mathrm{~s}$ in the present study). On the other hand, the bulk-explicit, bulkcond, and bin models are capable of accurately representing the real condensational growth time scale. To examine how often the condensational growth timescale exceeds the model time step, Fig. 15 shows the cumulative distribution function (CDF) of the condensational growth timescale for the bulkexplicit and bin model configurations. To minimize the effect of the initial conditions on the CDF, only data from the last $1.5 \mathrm{~h}$ of the simulations are included in the analysis. The vertical dashed line indicates the points at which the model time step coincides with the condensational growth time scale and the horizontal dashed line represents the 50th percentile (i.e., the median). While in both model configurations, the condensational time scale for some points is less than the model time step, most of the points are greater than the model time step, where the saturation adjustment scheme (or the equilibrium assumption) is invalid. For the bin model, this constitutes between $65 \%$ and $80 \%$ for the "Clean" and "Polluted" conditions and for the bulk-explicit model, between $95 \%$ and $97 \%$ of the points lie beyond the model time step. Thus, in the majority of the cloud, the saturation adjustment scheme will overpredict condensational growth (and, consequently, the latent heat release aloft that ultimate leads to complex dynamical feedbacks).

Whether or not there is a net overprediction of condensation and latent heating over the depth of the cloud using saturation adjustment depends upon the equilibrium value of the explicit supersaturation. The net error increases with larger values of equilibrium supersaturation; if the equilibrium supersaturation is zero then there is no net error in the condensation rate using saturation adjustment, although there may still be errors in the vertical distributions of condensation and heating. All else being equal, equilibrium supersaturation will be higher for stronger updrafts and lower droplet concentrations. Thus, the net error will be greatest using saturation adjustment applied to strong updrafts in clean conditions, and smaller in weak updrafts or polluted conditions. This dependence on aerosol loading implies a different magnitude of error in the response of the condensation rate and hence latent heating to polluted and pristine conditions using saturation adjustment. This is consistent with differences in the response of the average convective mass flux using the bulk-original model with saturation adjustment compared to bulk-explicit or bin.

Note that there are complications to this general picture. In updrafts that substantially increase in intensity with height, as is generally the case for moist deep convection, supersaturation may increase with height even in the cloud interior well above cloud base (as demonstrated in Fig. 13). This effect will exacerbate the net overprediction of condensation rate and latent heating using saturation adjustment. Moreover, droplet concentration can decrease with height in the cloud due to collision-coalescence, increasing the supersaturation relaxation timescale. In the absence of additional droplet activation, this can lead to large values of supersaturation inside the cloud (Clark, 1973), which again increases errors in the net condensation rate and heating over the depth of the cloud using saturation adjustment.

We note that a similar situation occurs for moist downdrafts. If the supersaturation (evaporation) timescale is short compared to the model time step, conditions are near equilibrium and saturation adjustment is a good approximation. However, in non-equilibrium conditions, such as in an accelerating downdraft, saturation adjustment may produce noticeable error in the evaporation rates and hence latent cooling.

To briefly summarize, saturation adjustment produces errors in strongly non-equilibrium conditions, when the supersaturation relaxation timescale is much longer than the model time step. This occurs near cloud base, especially in strong updrafts, and in the cloud interior when convective updrafts increase in intensity with height or when droplet number concentration is reduced as a result of collision-coalescence. On the other hand, saturation adjustment is a good approximation in other circumstances. In models with a relatively large grid spacing and long time step or in environments with weak vertical motion, supersaturation will be closer to equilibrium through most of the depth of the cloud and hence errors in the vertical distribution of condensation/evaporation rate using saturation adjustment will be small. Moreover, equilibrium supersaturation will be close to zero in weak updrafts, implying little error in net condensation over the depth of the cloud. However, we note that even though there may limited error in the condensation rate using saturation adjustment in this situation, large errors can occur in the peak supersaturation (near cloud base) and hence droplet number concentration in models that explicitly predict droplet activation as a function of supersaturation. Without performing detailed simulations using the microphysics models presented herein applied to other cases, this discussion serves to provide a conceptual view of the applicability of saturation adjustment in models. Detailed analysis of situations for which saturation adjustment is expected to produce little error is beyond the scope of this paper. 


\section{Conclusions}

Previous studies of aerosol effects on convective development and cumulative precipitation have hypothesized that results using bin and bulk microphysics models do not agree because of the use of a saturation adjustment scheme, which is commonly employed in bulk microphysics models (e.g., Khain and Lynn, 2009; Lebo and Seinfeld, 2011; Fan et al., 2012). To quantitatively address this issue, we employ a high-resolution CRM to study the effects of increased aerosol loading on a supercell storm using four microphysics model configurations:

1. Bin Model - All hydrometeors are represented using binned distributions following Lebo and Seinfeld (2011). Supersaturation is predicted explicitly over the course of a time step by accounting for dynamical tendencies, adiabatic cooling, and condensational growth.

2. Bulk-explicit Model - The two-moment bulk microphysics scheme of Morrison et al. (2009) is used without a saturation adjustment scheme. An algorithm, analogous to that used in the bin model, is used to more accurately predict the supersaturation over a time step for both droplet condensational growth and activation.

3. Bulk-Cond Model - The two-moment bulk microphysics scheme of Morrison et al. (2009) is used without a saturation adjustment scheme and droplet condensation is calculated from the explicit supersaturation as in the bulk-explicit and bin models. A pseudo-saturation adjustment scheme is employed, in which at the end of the microphysics routine, dummy variables for temperature and water vapor mixing ratio are saved and used to predict the supersaturation on the subsequent time step, after advection, for activation only.

4. Bulk-original Model - The two-moment bulk microphysics scheme of Morrison et al. (2009) is used with a saturation adjustment scheme applied to both droplet condensational growth and activation.

The results presented herein demonstrate, as suggested previously (e.g., Rosenfeld et al., 2008; Khain et al., 2008; Lebo and Seinfeld, 2011), the ability of an increase in the ambient aerosol number concentration to invigorate (or weaken) convection. The key results are summarized as follows:

1. The cumulative precipitation predicted using the bin model had the largest sensitivity to an increase in aerosol loading $(17.5 \%)$ while the change predicted by the bulk model configurations was quite small $(\sim$ $\pm 2.5 \%$ ). It was shown that the bin model predicts a larger increase in ice growth and hence graupel mean size in polluted compared to pristine conditions relative to the bulk model configurations, ultimately leading to a greater increase in rain water production and surface precipitation.
2. Simulations with the bulk-explicit and bulk-cond model configurations exhibited little difference in the convective mass flux, precipitation, and cold pool strength, owing to the fact that for deep convective clouds with strong updrafts and high supersaturations, the activation of new droplets is insensitive to the method by which the supersaturation is calculated (i.e., nearly all of the aerosol population activates regardless of the method used to calculate supersaturation).

3. The bulk-explicit and bin models predicted a small but robust invigoration, as shown by an increase in the timeand domain-averaged convective mass flux of 2.52 to 5.09 and 4.73 to $6.43 \%$, respectively, while the bulkoriginal model configuration predicted a small decrease of -1.75 to $-3.65 \%$. The invigoration predicted by the bulk-explicit and bin models was related to an increase in latent heating aloft with an increase in aerosol loading. The bulk-original model did not predict such an increase, and instead predicted more latent heating for the "Clean" aerosol scenario.

4. Simulated cold pool strength (as measured by the average lowest level perturbation $\theta$ within the cold pool) was shown to weaken under higher aerosol loading. The weakening was greatest for the original-bulk model configuration (6.52 to $13.1 \%)$. The bulk-explicit and bin models predicted a much smaller weakening $(0.87$ to $9.35 \%$ and -2.36 to $3.90 \%$, respectively), and so the response of the convective dynamics to increased aerosol loading was associated more with increased latent heating and buoyancy aloft than changes in the cold pool.

Figures 11 and 15 show quantitatively the effect of saturation adjustment on the supersaturation evolution and thus condensation rate and latent heating as well as the number of points in which the saturation adjustment assumption is invalid. Model simulations (Fig. 11) show that the bulkoriginal model predicts more latent heating relative to the bulk-explicit model, especially below about $9 \mathrm{~km}$. In order for the aerosol effect on convective strength to be the same between the two model configurations, the differences in latent heating between the models for each aerosol scenario ought to be the same. However, the differences are shown to be quite large (much more heating in the bulk-original model in the "Clean" case compared to "Polluted"). This is consistent with differences in the response of the convective dynamics between bulk-original and bulk-explicit, bulkcond, or bin. The bulk-original model overpredicts condensation (and hence latent heating) by forcing the saturation ratio to unity at the end of each time step in non-equilibrium conditions when the supersaturation should be increasing. Here, the model time step is shorter than the condensation time scale such that the grid box remains supersaturated at the end of the time step using the explicit treatment of 
supersaturation, unlike that which is predicted using the saturation adjustment scheme. This overprediction is consistent with large differences in the heating rates predicted by the bulk-original and bulk-explicit model configurations. Moreover, saturation adjustment schemes cannot capture changes in supersaturation, condensation, and latent heating resulting directly from differences in droplet concentration and size and hence the efficiency of vapor uptake between polluted and clean conditions. Overall, these differences in the models' physics explain much of the difference in the response of the convective dynamics between the bulk-original and bin models. However, the use of a saturation adjustment scheme cannot explain large differences in the response of surface precipitation to aerosol loading between the bin and bulk schemes. Results suggest that differing treatments of sedimentation, ice particle growth, or other microphysical factors contributed to these differences. A more detailed analysis of possible reasons for differences in the response of surface precipitation between the bulk and bin models is left for future work.

Acknowledgements. This work was supported by the Office of Naval Research grant N00014-10-1-0200. Computations were carried out on the CITerra cluster of the Geological and Planetary Sciences Division at Caltech. HM acknowledges partial support from NOAA grant NA08OAR4310543, US DOE ARM DE-FG0208ER64574, and the NSF Science and Technology Center for Multiscale Modeling of Atmospheric Processes (CMMAP), managed by Colorado State University under cooperative agreement ATM-0425247.

Edited by: P. Spichtinger

\section{References}

Albrecht, B.: Aerosols, cloud microphysics, and fractional cloudiness, Science, 245, 1227-1230, doi:10.1126/science.245.4923.1227, 1989.

Chuang, P. Y., Charlson, R. J., and Seinfeld, J. H.: Kinetic limitations on droplet formation in clouds, Nature, 390, 94-96, 1997.

Clark, T. L.: Numerical Modeling of the Dynamics and Microphysics of Warm Cumulus Convection, J. Atmos. Sci., 30, 857878, 1973.

Dawson II, D. T., Xue, M., Milbrandt, J. A., and Yau, M. K.: Comparison of evaporation and cold pool development between single-moment and multi-moment bulk microphysics schemes in idealized simulations of tornadic thunderstorms, Mon. Weather Rev., 138, 1152-1171, 2010.

Ekman, A. M. L., Engstrom, A., and Soderberg, A.: Impact of twoway aerosol-cloud interaction and changes in aerosol size distribution on simulated aerosol-induced deep convective cloud sensitivity, J. Atmos. Sci., 68, 685-697, 2011.

Fan, J., Zhang, R., Li, G., and Tao, W.-K.: Effects of aerosols and relative humidity on cumulus clouds, J. Geophys. Res., 112, D14204, doi:10.1029/2006JD008136, 2007.
Fan, J., Yuan, T., Comstock, J. M., Ghan, S., Khain, A., Leung, L. R., Li, Z., Martins, V. J., and Ovchinnikov, M.: Dominant role by vertical wind shear in regulating aerosol effects on deep convective clouds, J. Geophys. Res., 114, D22206, doi:10.1029/2009JD012352, 2009.

Fan, J., Leung, L. R., Li, Z., Morrison, H., Chen, H., Zhou, Y., Qian, Y., and Wang, Y.: Aerosol impacts on clouds and precipitation in easter China: Results form bin and bulk microphysics, J. Geophys. Res., 117, D00K36, doi:10.1029/2011JD016537, 2012.

Grabowski, W. W. and Morrison, H.: Indirect Impact of Atmospheric Aerosol in Idealized Simulations of ConvectiveRadiative Quasi Equilibrium. Part II: Double-moment microphysics, J. Climate, 24, 1897-1912, 2011.

Grabowski, W. W.: Indirect Impact of Atmospheric Aerosol in Idealized Simulations of Convective-Radiative Quasi Equilibrium., J. Climate, 19, 4664-4682, 2006.

Gunn, R. and Phillips, B. B.: An experiment investigation of the effect of air pollution on the initiation of rain, J. Meteorol., 14, 272-280, 1956.

Hallett, J. and Mossop, S. C.: Production of secondary ice particles during the riming process, Nature, 249, 26-28, doi:10.1038/249026a0, 1974.

Harrington, J. Y., Feingold, G., and Cotton, W. R.: Radiative impacts on the growth of a population of drops within simulated summertime Arctic stratus, J. Atmos. Sci., 57, 766-785, 2000.

Houze, R. A.: Cloud Dynamics, vol. 53 of International Geophysics Series, Academic Press, Inc., San Diego, California, USA, 1993.

James, R. P. and Markowski, P. M.: A numerical investigation of the effects of dry air aloft on deep convection, Mon. Weather Rev., 138, 140-161, 2010.

Khain, A. and Lynn, B.: Simulation of a supercell storm in clean and dirty atmosphere using weather research and forecasting model with spectral bin microphysics, J. Geophys. Res., 114, D19209, doi:10.1029/2009JD011827, 2009.

Khain, A. and Pokrovsky, A.: Simulation of effects of atmospheric aerosols on deep turbulent convective clouds using a spectral microphysics mixed-phase cumulus cloud model. Part II: Sensitivity study, J. Atmos. Sci., 61, 2983-3001, 2004.

Khain, A., Pokrovsky, A., Pinsky, M., Seifert, A., and Phillips, V.: Simulation of effects of atmospheric aerosols on deep turbulent convective clouds using a spectral microphysics mixed-phase cumulus cloud model. Part I: Model description and possible applications, J. Atmos. Sci., 161, 2963-2982, 2004.

Khain, A., Rosenfeld, D., and Pokrovsky, A.: Aerosol impact on the dynamics and microphysics of deep convective clouds, Quart. J. Roy. Meteor. Soc., 131, 2639-2663, doi:10.1256//qj.04.62, 2005.

Khain, A., BenMoshe, N., and Pokrovsky, A.: Factors Determining the Impact of Aerosols on Surface Precipitation from Clouds: An Attempt at Classification, J. Atmos. Sci., 65, 1721-1748, 2008.

Klemp, J. B.: Dynamics of tornadic thunderstorms, Am. Rev. Fluid Mech., 19, 369-402, 1987.

Kogan, Y. L. and Martin, W. J.: Parameterization of Bulk Condensation in Numerical Cloud Models, J. Atmos. Sci., 51, 1728-1739, 1994.

Koren, I., Kaufman, Y. J., Rosenfeld, D., Remer, L. A., and Rudich, Y.: Aerosol invigoration and restructuring of Atlantic convective clouds, Geophys. Res. Let., 32, doi:10.1029/2005GL023187, 2005. 
Koren, I., Remer, L. A., Altaratz, O., Martins, J. V., and Davidi, A.: Aerosol-induced changes of convective cloud anvils produce climate warming, Atmos. Chem. Phys., 10, 5001-5010, doi:10.5194/acp-10-5001-2010, 2010.

Lebo, Z. J. and Seinfeld, J. H.: Theoretical basis for convective invigoration due to increased aerosol concentration, Atmos. Chem. Phys., 11, 5407-5429, doi:10.5194/acp-11-5407-2011, 2011.

Lee, S. S.: Dependence of aerosol-precipitation interactions on humidity in a multiple-cloud system, Atmos. Chem. Phys., 11, 2179-2196, doi:10.5194/acp-11-2179-2011, 2011.

Lee, S. S., Donner, L. J., Phillips, V. T. J., and Ming, Y.: Examination of aerosol effects on precipitation in deep convective clouds during the 1997 ARM summer experiment, Quart. J. Roy. Meteor. Soc., 134, 1201-1220, doi:10.1002/qj.287, 2008a.

Lee, S. S., Donner, L. J., Phillips, V. T. J., and Ming, Y.: The dependence of aerosol effects on clouds and precipitation on cloudsystem organization, shear and stability, J. Geophys. Res., 113, doi:10.1029/2007JD009224, 2008b.

Li, G., Wang, Y., Lee, K.-H., Diao, Y., and Zhang, R.: Impacts of aerosols on the development and precipitation of a mesoscale squall line, J. Geophys. Res., 114, doi:10.1029/2008JD011581, 2009.

Milbrandt, J. A. and Yau, M. K.: A multi-moment bulk micriphysics parameterization. Part IV: Sensitivity experiments, J. Atmos. Sci., 63, 3137-3159, 2006.

Mitchell, D. L.: Use of Mass- and area-dimensional power laws for determining precipitation particle terminal velocities, J. Atmos. Sci., 53, 1710-1713, 1996.

Morrison, H.: On the robustness of aerosol effects on an idealized supercell storm simulated with a cloud system-resolving model, Atmos. Chem. Phys., 12, 7689-7705, doi:10.5194/acp-12-76892012, 2012.

Morrison, H. and Grabowski, W. W.: Modeling supersaturation and sub-grid scale mixing with two-moment warm bulk microphysics, J. Atmos. Sci., 65, 792-812, 2008.

Morrison, H. and Milbrandt, J. A.: Comparison of two-moment bulk microphysics schemes in idealized supercell thunderstorm simulations, Mon. Weather Rev., 139, 1103-1130, 2011.

Morrison, H., Thompson, G., and Tatarskii, V.: Impact of Cloud Microphysics on the Development of Trailing Stratiform Precipitation in a Simulated Squall Line: Comparison of One- and TwoMoment Schemes, Mon. Weather Rev., 137, 991-1007, 2009.

Noppel, H., Blahak, U., Seifert, A., and Beheng, K. D.: Simulations of a hailstorm and the impact of CCN using an advanced twomoment cloud microphysics scheme, Atmos. Res., 96, 286-301, 2010.

Pruppacher, H. R. and Klett, J. D.: Microphysics of Clouds and Precipitation, Kluwer Academic Publishers, Boston, 1997.

Reisin, T., Levin, Z., and Tzivion, S.: Rain production in convective clouds as simulated in an axisymmetric model with detailed microphysics. Part I: Description of the model, J. Atmos. Sci., 53, 497-519, 1996.

Rosenfeld, D., Lohmann, U., Raga, G. B., O’Dowd, C. D., Kulmala, M., Fuzzi, S., Reissell, A., and Andreae, M. O.: Flood or Drought: How do aerosols affect precipitation?, Science, 321, 1309-1313, 2008.

Rotunno, R., Klemp, J. B., and Weisman, M. L.: A theory for strong, long-lived squall lines, J. Atmos. Sci., 45, 463-485, 1988.
Seifert, A. and Beheng, K. D.: A two-moment cloud microphysics parameterization for mixed-phase clouds. Part 2: Maritime vs. continental deep convective storms, Meteor. Atmos. Phys., 92, 45-66, 2006.

Seifert, A., Khain, A., Pokrovsky, A., and Beheng, K.: A Comparison of Spectral Bin and Two-Moment Bulk Mixed-Phase Cloud Microphysics, Atmos. Res., 80, 146-166, 2006.

Seifert, A., Köhler, C., and Beheng, K. D.: Aerosol-cloudprecipitation effects over Germany as simulated by a convectivescale numerical weather prediction model, Atmos. Chem. Phys., 12, 709-725, doi:10.5194/acp-12-709-2012, 2012.

Skamarock, W. C., Klemp, J. B., Dudhia, J., Gill, D. O., Barker, D. M., Duda, M. G., Huang, X.-Y., Wang, W., and Powers, J. G.: A description of the advanced research WRF Version 3, National Center for Atmospheric Research, Boulder, Colorado, USA, 2008.

Squires, P.: The microstructure and Colloidal Stability of Warm Clouds: Part I - The Relation between Structure and Stability, Tellus, 10, 256-261, 1958.

Stevens, B. and Feingold, G.: Untangling aerosol effects on clouds and precipitation in a buffered system, Nature, 461, 607-613, doi:10.1038/nature08281, 2009.

Stevens, B., Feingold, G., Cotton, W. R., and Walko, R. L.: Elements of the microphysical structure of numerically simulated nonprecipitating stratocumulus, J. Atmos. Sci., 53, 980-1006, 1996.

Stevens, B., Moeng, C.-H., Ackerman, A. S., Bretherton, C. S., Chlond, A., De Roode, S., Edwards, J., Golaz, J., Jiang, H., Khairoutdinov, M., Kirkpatrick, M. P., Lewellen, D. C., Lock, A., Muller, F., Stevens, D. E., Whelan, E., and Zhu, P.: Evaluation of large-eddy simulations via observations of nocturnal marine stratocumulus, Mon. Weather Rev., 133, 1443-1462, 2005.

Tao, W.-K., Li, X., Khain, A., Matsui, T., Lang, S., and Simpson, J.: Role of atmospheric aerosol concentration on deep convective precipitation: Cloud-resolving model simulations, J. Geophys. Res., 112, doi:10.1029/2007JD008728, 2007.

Tao, W.-K., Chen, J., Li, Z., Wang, C., and Zhang, C.: Impact of aerosols on convective clouds and precipitation, Rev. Geophys., 50, 1-62, 2012.

Teller, A. and Levin, Z.: The effects of aerosols on precipitation and dimensions of subtropical clouds: a sensitivity study using a numerical cloud model, Atmos. Chem. Phys., 6, 67-80, doi:10.5194/acp-6-67-2006, 2006.

Van den Heever, S. C. and Cotton, W. R.: The impact of hail size on simulated supercell storms, J. Atmos. Sci., 61, 1596-1609, 2004.

Van den Heever, S. C. and Cotton, W. R.: Urban Aerosol Impacts on Downwind Convective Storms, J. Appl. Meteor. Clim., 46, 828-850, 2007.

Van den Heever, S. C., Carri, G. G., Cotton, W. R., DeMott, P. J., and Prenni, A. J.: Impacts of Nucleating Aerosol on Florida Storms. Part I: Mesoscale Simulations, J. Atmos. Sci., 63, 1752-1775, 2006.

Van den Heever, S. C., Stephens, G. L., and Wood, N. B.: Aerosol indirect effects on tropical convection characteristics under conditions of radiative-convective equilibrium, J. Atmos. Sci., 68, 699-718, 2011.

Wang, C.: A modeling study of the response of tropical deep convection to the increase of cloud condensation nuclei concentration: 1. Dynamics and microphysics, J. Geophys. Res., 110, 
D21211, doi:10.1029/2004JD005720, 2005.

Weisman, M. L. and Klemp, J. B.: The dependence of numerically simulated convective storms on vertical wind shear and buoyancy, Mon. Weather Rev., 110, 504-520, 1982.

Weisman, M. L. and Klemp, J. B.: The structure and classification of numerically simulations convective storms in directionally varying wind shears, Mon. Weather Rev., 112, 2479-2498, 1984.
Weisman, M. L. and Rotunno, R.: "A theory for strong long-lived squall lines" revisited, J. Atmos. Sci., 61, 361-382, 2004.

Xue, H. and Feingold, G.: Large-eddy simulations of trade wind cumulus: Investigation of aerosol indirect effects, J. Atmos. Sci., 63, 1605-1622, 2006. 